\title{
EXECUTIVE FUNCTIONS AND PARENTING STRESS IN MOTHERS WITH PROBLEMATIC SUBSTANCE USE
}

\author{
by \\ Victoria Ingram \\ BAH Queen's University 2005, MA York University 2007, BSCH York University 2016 \\ A thesis presented to Ryerson University \\ in partial fulfillment of the requirements for the degree of \\ Master of Arts in the Program of Psychology
}

Toronto, Ontario, Canada, 2018

(C) Victoria Ingram, 2018 


\section{AUTHOR'S DECLARATION FOR ELECTRONIC SUBMISSION OF A THESIS}

I hereby declare that I am the sole author of this thesis. This is a true copy of the thesis, including any required final revisions, as accepted by my examiners.

I authorize Ryerson University to lend this thesis to other institutions or individuals for the purpose of scholarly research.

I further authorize Ryerson University to reproduce this thesis by photocopying or by other means, in total or in part, at the request of other institutions or individuals for the purpose of scholarly research.

I understand that my thesis may be made electronically available to the public. 


\section{EXECUTIVE FUNCTIONS AND PARENTING STRESS IN MOTHERS WITH}

\section{PROBLEMATIC SUBSTANCE USE}

Master of Arts, 2018

Victoria Ingram

Psychology

Ryerson University

\section{ABSTRACT}

A growing body of research has shown that executive functions play an important role in effective and sensitive parenting. No studies have examined this relation in mothers with problematic substance use, who may be at particular risk given biological, psychological, and contextual risks that may undermine executive functions and increase parenting stress. The purpose of this study was to investigate the relation between three executive functions and parenting stress. Sixty-five mothers attending substance use treatment completed tasks assessing updating, inhibition, and shifting executive functions and questionnaires assessing parenting stress, reflecting both relational and household chaos definitions of the construct. Controlling for SES and age of youngest child, lower performance on both inhibition and updating tasks was associated with increased parenting stress, when a relational definition was employed. However, no significant relations were found between executive functions and household chaos definitions of parenting stress, after depression and SES were controlled for. These preliminary results suggest a role for executive functions in parenting stress in mothers with problematic substance use, but highlight the importance of considering the type of executive function assessed and the definition of parenting stress employed. Directions for future research and clinical implications are discussed. 


\section{Acknowledgments}

I am so grateful to all the individuals who have supported me in the completion of this research. Above all, my sincerest gratitude to my supervisor and mentor, Dr. Karen Milligan, whose constant encouragement, guidance and support have helped me to conceptualize and implement this project. Her commitment to improving the lives of mothers with problematic substance use is a daily inspiration to me. I would also like to thank Dr. Leslie Atkinson for his many insights during this process that have helped me to broaden my thinking and strengthen this research. Finally, I am truly appreciative of Dr. Naomi Koerner for her feedback and interest as part of my examining committee.

There are other members of the Ryerson community who have played an important role in this research. I am truly indebted to Carson Pun for his technological expertise, and his ever patient willingness to support me in this study. My lab mates, Tamara Meixner and Annabel Sibalis have been continuous sources of encouragement and mentorship. Finally, I have been truly blessed to travel this journey with a wonderful cohort of students, who are incredibly collaborative and generous with their insights and friendship.

Without the participation of the integrated treatment sites, and their clients, this research would not have been possible. I am so grateful to the leadership, staff and mothers who gave their time and energy in support of this study.

I also must thank my husband, Nadim Kara, and my little daughter, Tahlia, who help me each day to strive for difficult goals, and feel confidence that I can achieve them. I love you both very much.

Finally, I would like to acknowledge with gratitude the funding that was awarded to me by the Social Sciences and Humanities Research Council and the Ontario Ministry of Training, Colleges, and Universities throughout my Master's program. 


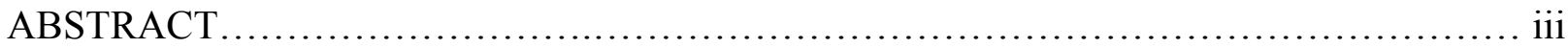

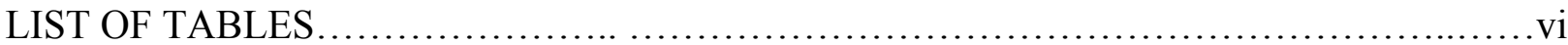

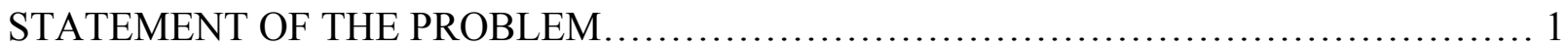

\section{INTRODUCTION}

1.1 Maternal Substance Use and Motherhood.................................................................. 4

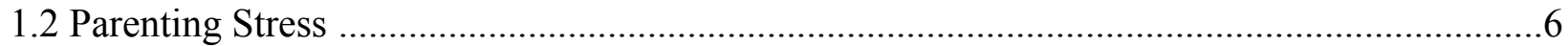

1.3 Parenting Stress among Mothers with Problematic Substance Use...................................10

1.4 Factors that Contribute to Parenting Stress in the Context of Problematic Substance Use.... 10

1.5 Maternal Executive Functions and Parenting Stress...................................................... 13

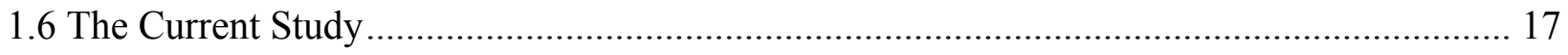

\section{METHOD}

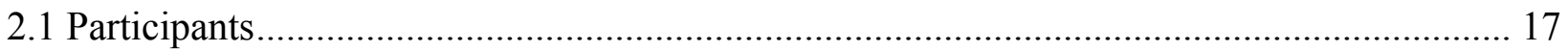

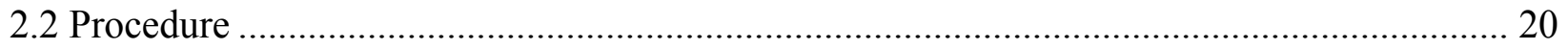

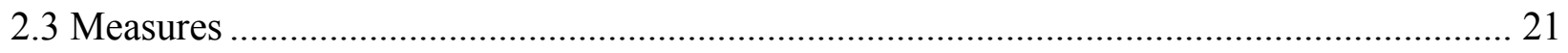

2.3.1 Parenting Stress: P-C-R Model ...................................................................... 21

2.3.2 Household Chaos: DH Model .................................................................................... 21

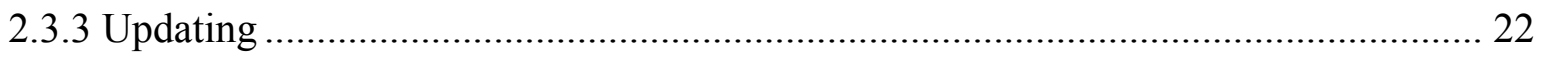

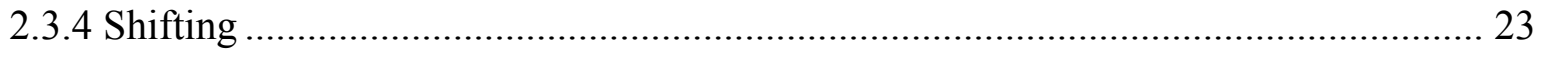

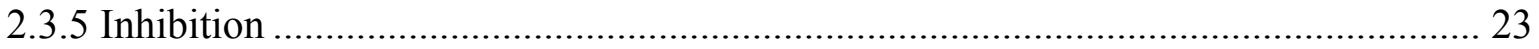

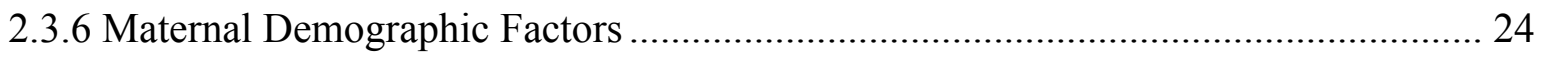

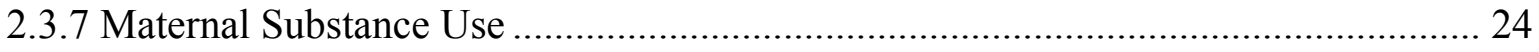

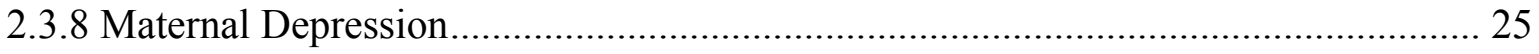

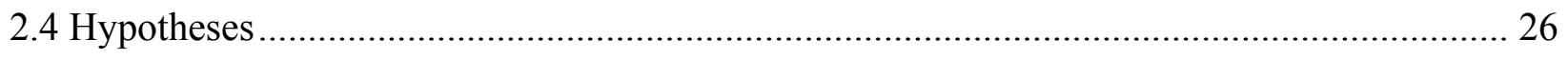

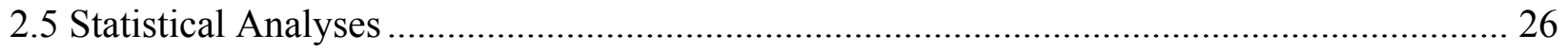

\section{RESULTS}

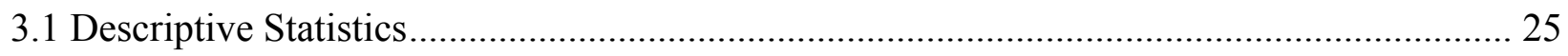

3.2 Correlations between Executive Function and Stress Measures....................................... 27

3.3 Executive Functions, Parenting Stress and Household Chaos .......................................... 29 


\section{DISCUSSION}

4.1. Executive Functions and Parenting Stress: The Need for Executive Function Specificity...32

4.1.1 Specifying the Parenting Stress Construct.................................... 36

4.1.2 Additional Variables Contributing to Parenting Stress............................38

4.2 Methodological Limitations and Future Directions...............................41

4.2.1 Directionality of Relations......................................... 41

4.2.2 Measurement of Executive Functions...................................43

4.2.3 Measurement of Executive Functions: The Role of Emotion.....................44

4.2.4 Parenting Stress: A Complex Construct ................................46

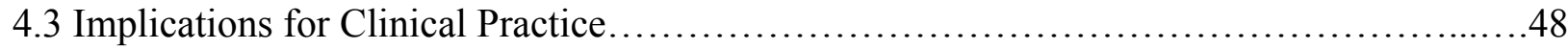

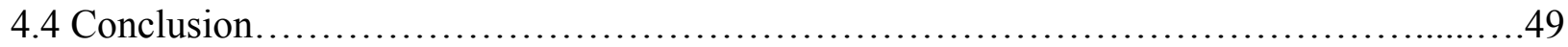

References............................51 


\section{List of Tables}

Table 1: Participant Demographic Characteristics ............................................................. 19

Table 2: Descriptive Statistics for Executive Functions and Parenting Stress and Household

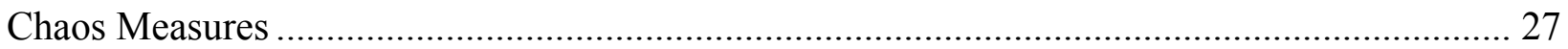

Table 3: Pearson Correlations for Executive Function and Parenting Stress Measures .............. 28

Table 4: Regression of PSI-SF-4 Total Stress on Updating, Shifting and Inhibition Functions.. 30

Table 5: Regression of CHAOS on Updating, Shifting and Inhibition Functions ..................... 31 


\section{Statement of the Problem}

Problematic substance use among women is on the rise in Canada and is associated with a range of significant psychological, social, legal and familial consequences (Canadian Network of Substance Abuse and Allied Professionals, 2013). Studies highlight parenting challenges associated with chronic problematic substance use, including increased risk for insecure attachments with children, less warm and sensitive response styles to child cues, and coercive and harsh parenting behaviours (Cyr, Euser, Bakermans-Kranenburg, \& VanIjzendoorn, 2010; Dunn, Tarter, Mezzich, Vanyukov, Kirisci, \& Kirillova, 2002; O’Connor, Kogan \& Findley, 2002; Rodning, Beckwith, \& Howard, 1991; Walsh, MacMillan, \& Jamieson, 2003). Being raised within the context of such risks may, among other risk factors, increase the likelihood of negative physical, mental and emotional health outcomes for children (Motz, Leslie, Pepler, Moore, \& Freeman, 2006).

Substance use alone does not account for heightened parenting risk. Mothers with problematic substance use are more likely to live in conditions of high risk and adversity that may increase stress and undermine effective problem-solving, emotion regulation, and parenting. Women with problematic substance use are more likely to experience mental health difficulties (e.g., depression, anxiety) and to have experienced trauma in childhood or adulthood (Leigh \& Milgrom, 2008; Sheinkopf et al., 2005; Williford, Calkins \& Keane, 2007). They are also more likely to have low social support and low socio-economic status (Steele et al., 2016; Finkelstein, 1994). Substance-related factors also increase the likelihood of stress within the parenting role, as these mothers are often stigmatized and at risk of child welfare involvement (Berger, Slack, Waldfogel, \& Bruch, 2010; Mayer, Lavergne, \& Baraldi, 2004). Moreover, women’s engagement 
in treatment is often met with barriers to engaging in care, including lack of child care, and stigma (Niccols \& Sword, 2005). Significant stress-related vulnerability also arises from the neurobiological impact of substances. Mothers may experience heightened stress reactivity and stress regulation difficulties in part due to the impact of substances, such as alcohol and cocaine, on neural and hormonal pathways (Rutherford, Potenza, \& Mayes, 2013; Sinha, 2008). In addition, problematic substance use may disrupt parenting-related motivation and reward pathways due to overlap with addiction and craving processes at the neural level (Landi et al., 2011; Rutherford et al., 2011).

While the experience of stress is common among parents, mothers with problematic substance use have been shown to experience higher levels of parenting stress (Kelley, 1992; Kelley 1998). Reductions in parenting stress in this population significantly improve child and parent outcomes over time (Killeen \& Brady, 2000). As such, reducing parenting stress is an important target for early intervention. Identification of those mothers who may benefit most from early intervention may not only aid in engaging those at risk in treatment but may also inform the development and tailoring of parenting interventions for this population (Williford et al., 2007).

While contextual factors such as poverty and maternal factors such as depression have a well-established impact on parenting stress (Hur, Buettner, \& Jeon, 2015; Steele et al., 2016), attention has recently been centered on neuropsychological factors and their impact on parenting stress and parenting outcomes more generally (Crandall, Deater-Deckard, \& Riley 2015). Executive functions have been at the forefront of this exploration. Executive functions consist of a number of separate but related higher-order cognitive processes that support effective problemsolving and goal-directed behaviour (Friedman \& Miyake, 2017). Three main executive 
functions are frequently identified: updating (i.e., the ability to keep information in mind while working with that information, also known as working memory), inhibition (i.e., the ability to stop and think before responding), and shifting (i.e., the ability to shift in terms of thoughts or responses) (Friedman \& Miyake, 2017). Recent research suggests that parents with increased executive function difficulties experience more parenting challenges (Crandall et al., 2015). Despite the cumulative potential risk for these challenges in mothers with problematic substance use, no known studies have explored the relation between executive functions and parenting stress in this population (Rutherford et al., 2013). In fact, parental substance use disorder has often been an exclusionary criterion. Overall, the current study was designed to address this gap in the extant literature by exploring the association between maternal executive functions on parenting stress in mothers with problematic substance use. 


\section{INTRODUCTION}

\subsection{Maternal Substance Use and Motherhood}

Rates of substance use are on the rise for females in Canada (Canadian Network of Substance Abuse and Allied Professionals, 2013). Approximately, 10.3\% of Canadian women (15 years and older) used an illicit drug (e.g., cocaine, methamphetamine, hallucinogen, ecstasy, heroin) in 2015, while $12.7 \%$ of women endorsed consumption patterns exceeding low-risk drinking recommendations on a weekly basis (Government of Canada, 2015). Problematic substance use is associated with a range of significant psychological, social, legal and familial consequences. Among female users of illicit drugs, 31.6\% report at least one harm related to their substance use, such as physical health difficulties, social and professional impacts, or legal and housing problems (Canadian Network of Substance Abuse and Allied Professionals, 2013). Women also show sex-related vulnerabilities, including being more vulnerable to the physical consequences of substances at a lower dose and exposure compared to men (National Centre on Addiction and Substance Abuse, 2003). Challenges with mental health are highly prevalent. More than two-thirds of women with problematic substance use have a comorbid mental health disorder, such as a mood, anxiety, or eating disorder and/or borderline personality disorder (Trull, Sher, Minks-Brown, Durbin, \& Burr, 2000; Zilberman, Tavares, Blume \& El-Guebaly, 2003). The majority of women with problematic substance use have also been exposed to trauma, such as abuse and neglect in childhood and/or interpersonal trauma and violence in adulthood (Hien, Cohen, \& Campbell, 2005; Horrigan, Schroeder, \& Schaffer, 2000).

A sex-specific role held by most women in substance use treatment is motherhood (Grella, Hser, \& Yu-Chuang, 2006). Motherhood can both facilitate and hinder changing patterns of problematic substance use. On one hand, it can motivate change in substance use. Women 
who are pregnant or parenting may be more likely to approach this challenge compared to nonmothers due to fears about losing child custody, as well as desires to improve their ability to parent, and/or improve the family context their children grow up in. However, parenting can also bring significant challenge and stress, which can serve to perpetuate patterns of problematic substance use (Milligan et al., 2010; Niccols, Milligan, Sword, Thabane, Henderson \& Smith, 2012). Parenting practices that are punitive or associated with child neglect or abuse (i.e., inadequate supervision, lack of basic needs being met, aggression, or other forms of harm) are more prevalent in women with problematic substance use than the general population (Dunn et al., 2002; O'Connor et al., 2006; Walsh et al., 2003). There are multiple factors that may underlie parenting challenges. Women may experience more challenge with mentalizing, (i.e., the ability to envision the thoughts, feelings and desires of children), a skill that supports emotional availability and regulation of child affect (Borelli, West, Decoste, \& Suchman, 2012; Molitor, Mayes \& Ward, 2003; Söderström, \& Skårderud, 2009). Maternal emotion regulation challenges may reduce the ability to down regulate anger and make accurate attributions in the context of parenting children (Suchman, DeCoste, Leigh \& Borelli, 2010). Higher levels of intrusiveness and difficulties with establishing predictable, structured routines are also more common in this population (Salo et al., 2010). Neurobiological sequelae of chronic substance use on neural reward systems may render child cues less salient for women making it more difficult to engage with children in a sensitive manner. For example, functional magnetic resonance imaging suggests that neural activation in response to infant cries and distressed infant faces is reduced in mothers with problematic substance use (Landi et al., 2011). Women, due to their own lived experience in their families of origin, may also have limited experience with positive parenting models and limited knowledge of child development and positive parenting 
strategies (Velez et al., 2004). While most women experience parenting stress to some degree, the complex, cumulative risks experienced by many women with problematic substance use may magnify this risk (Rodriguez, 2010). In turn, parenting stress may increase risk for harsh parenting and physical discipline (Pinderhughes, Dodge, Bates, Pettit, \& Zelli, 2000), neglect, and continued patterns of problematic substance use to cope with challenges in the parenting role (Barnet, Duggan, Wilson \& Joffe, 1995).

\subsection{Parenting Stress}

The parenting role has long been identified as a source of stress for families and mothers in particular (Tufts, 1907; Williams, 1968). It was not until the 1980s, however, that the concept of parenting stress began to be systematically theorized and investigated (Loyd \& Abidin, 1985). According to Deater-Deckard (2004):

Parenting stress can be defined succinctly as a set of processes that lead to aversive psychological and physiological reactions arising from attempts to adapt to the demands of parenthood... Parenting stress involves a broad set of complex, dynamic processes linking the child and her behaviours, perceived demands of parenting, parenting resources, physiological reaction to the demands of parenting, qualities of the parent's relationships with the child and other family member, and links with other people and institutions outside of the home (p. 6).

Parenting stress is thus a broad construct, encompassing child, parent and environmental factors that contribute to a parent's ability to cope with and adapt to the parenting role, including: child and parent behaviours, child-parent relationship dynamics, perceived demands within the parenting role, level of available household resources (e.g., income, housing), available social supports (e.g., extended family, neighbours) and the presence of external stressors (e.g., job 
stress) (Deater-Deckard, 2004). Parenting stress also has a strong subjective component, with parent attributions regarding their child's behaviours, and perceptions of their own competence, significantly impacting on stress levels (Bugental \& Johnston, 2000). This includes increases in parenting stress when disparities exist between a parent's understanding of their actual resources (i.e., emotional, social, psychological, financial resources) and their expectations about the resources needed to meet parenting demands (Bugental \& Johnson, 2000; Goldstein, 1995). Finally, from a psychophysiological perspective, stress (including parenting stress) is associated with a biological response involving neurotransmitters and hormones that activate the sympathetic nervous system and prepare the body for 'fight, flight or freeze' responses (Lazarus, 1999). Chronic over-activation of this system related to parenting or other stressors can reduce its effectiveness in readying the body to cope with stress and promote a range of negative mental health and physical outcomes (Deater-Deckard, 2004). Parenting stress is thus a complex, wideranging construct that seeks to integrate potential biological, psychological and social influences on how a parent perceives and responds to the parenting role.

Two theoretical approaches have been commonly used to examine parenting stress. The most common is the parent-child-relationship (P-C-R) model developed by Abidin (1992), which theorizes that difficulties in one or more of three domains (parent factors, child factors, dyadic relationship factors) is associated with increased parenting stress (Abidin, 1992). Here, parent and child factors primarily involve internal attributes that impact functioning, including child and parent psychopathology (e.g., maternal depression, childhood behavioural problems), as well as parental perceptions of competence and resources (Deater-Deckard, 1994). This model highlights the bi-directional influence between parents and children, such that impacts to parent, child or parent-child relationship functioning are all viewed to potentially increase parenting 
stress (Abidin, 1992). In general, greater childhood difficulties and conflict in the child-parent relationship has been found to increase parenting stress and the risk of maltreatment in a transactional relationship across time (Margalit \& Kleitman, 2006).

Since its introduction, the P-C-R model has been examined extensively using self-report measures of parental perceptions of stress (Deater-Deckard, 2004). Most self-report measures of parenting stress identify levels of parental distress in terms of distress at the individual level (i.e., parental psychological health and functioning), and/or distress in the parenting role (i.e., concerns about parenting responsibilities, or the dyadic relationship) (Haskett, Ahern, Ward, \& Allaire, 2006). Indeed, parenting distress is highly correlated to parental depression and anxiety, with parenting stress acting as a strong predictor of the general health and well-being of the parent more generally (Costa, Weems, Pellerin, \& Dalton, 2006; Ponnet et al., 2013). As Hayes and Watson (2013) note, individual distress may arise from factors unrelated to parenting, yet current measures blur this distinction. Moreover, by focusing on perceptions of their distress and self-reports of their parental competence, current measures may place less emphasis on other observable indicators (e.g., environmental, behavioural) of parental stress.

A second model, Daily Hassles (DH) theory, is focused on these other observable indicators. This theory highlights the role of parent and child factors, but notes that parenting stress can still occur where clinical levels of parent or child dysfunction are not present. Thus, Crnic and Greenberg (1990) broaden Abidin's approach by noting that parenting stress can still arise from a daily accumulation of smaller hassles or stressors in the household (e.g. navigating childcare, routines or minor child illness) that build over time and reduce a parent's capacity to cope. This relationship is likely cumulative for a number of parents, with more minor daily hassles or lower-level chronic stressors having accumulating effects on the family system and 
child behaviour over time (Crnic, Gaze, \& Hoffman, 2005; Crnic \& Greenberg, 1990; Crnic \& Low, 2002). Importantly, experience of these daily household stressors are only of concern when they combine to cause considerable distress and dissatisfaction in the parenting role, while moderate and manageable levels of stress provide motivational arousal that can improve, rather than undermine, parental functioning (Deater-Deckard, 2004).

In keeping with the DH theory, household chaos is a construct used to describe levels of environmental disorganization and lack of structured routines within the home (Johnson, Martin, Brooks-Gunn \& Petrill, 2008). Household chaos was initially examined as an environmental characteristic influencing child development in the early 1970's (Cohen, Glass, \& Singer, 1973). In particular, studies sought to identify the role of high levels of crowding and noise and low levels of predictability (structural and temporal) in household routines (Coldwell, Pike \& Dunn, 2006). It has since been found that such conditions contribute to changes in physiological responses to stress among family members, altering regulation and reactivity to the biological stress response (Evans \& Kim, 2007; Gustafsson et al., 2010). Current measures of household chaos thus identify behavioural and environmental factors (e.g., lack of routine, rushing, interruptions) that can be understood as reflective of heightened household stress (Shapero \& Steinberg, 2013). In particular, high levels of household chaos may influence parenting through the disruption of appropriate social interactions between family members, as well as suggest parental difficulties in creating a calm, organized and predictable environment for the family. In their study, Whitesell and colleagues (2015) found that at high levels of household chaos, parents show lower emotional availability and lower-quality dyadic interactions before bedtime. As well, under conditions of noise-related household chaos, parents are more likely to report lower perceptions of self-efficacy compared to parents in more calm households (Corapci \& Wachs, 
2002). Additional studies have noted associations between household chaos and greater parental distress (i.e., depression, anxiety) and emotional dysregulation that may further undermine a parent's ability to recognize and respond to his/her child's needs in more chaotic homes (Ackerman \& Brown, 2010; Evans \& Lepore, 2008; Whitesell et al., 2015). By identifying behavioural and environmental factors that contribute to stress at the household level, measures of household chaos support evaluation of parenting stress consistent with a DH theoretical approach, highlighting environmental and behavioural indictors of household stress.

\subsection{Parenting Stress among Mothers with Problematic Substance Use}

Researchers examining parenting stress from a P-C-R perspective have found high prevalence of parenting stress among mothers with problematic substance use. Kelley (1998) found that $47 \%$ of mothers with problematic substance use reported total parenting stress in the clinical range, compared to $3.3 \%$ of mothers without problematic substance use matched on socio-economic and demographic variables. More recently, in their sample of methamphetamineusing mothers, Liles and colleagues (2012) found clinically significant perceptions of parenting stress in $24 \%$ of their sample. No studies to date have examined household chaos in mothers with problematic substance use. Thus, research is warranted to examine if there are differences in relationally-based perceptions of parenting stress and behavioural indicators of household chaos. Differentiating parenting stress using these two theoretical approaches may be helpful in identifying those at risk and tailoring interventions to reduce parenting stress.

\subsection{Factors that Contribute to Parenting Stress in the Context of Problematic Substance}

Use

Studies have examined factors that may contribute to heightened levels of parenting stress in mothers with problematic substance use. According to Nair and colleagues (2003), the 
severity of P-C-R perceived parenting stress among mothers with problematic substance use is associated with increasing levels of cumulative maternal risk factors. Mothers who experience five or more risk factors (including depression and mental health difficulties, experiences of violence, large family size, incarceration, lack of spouse/partner, negative life events) show significantly higher parenting stress and child abuse potential versus mothers with four or less risk factors. This knowledge is critical, as mothers with problematic substance use are much more likely to be exposed to a number of significant, often inter-related life stressors, including treatment-related stressors, child-related difficulties and personal stress.

With regards to treatment, significant stigma associated with being a mother using substances means that women experience considerable stress when choosing to engage in treatment or not (Niccols \& Sword, 2005). Parents with problematic substance use are highly likely to be the subject of child welfare investigation, making substance use disclosure a serious risk for any mother wishing to maintain custody (Berger et al., 2010; Mayer et al., 2004). Then, once in treatment, many residential facilities do not provide opportunities for mothers to continue to care for their children while in treatment, leaving mothers with a difficult choice between entering and staying in treatment, or maintaining their parental role (Neger \& Prinz, 2015). In many cases, caseworkers may also face pressure to resolve child custody cases quickly, and not give the mother adequate time to complete treatment before making decisions regarding final child placement (Dauber, Neighbors, Dasaro, Riordan, \& Morgenstern, 2012). With these system level barriers in play, mothers experience considerable stress when trying to balance the demands of treatment and parenting, conditions further magnified in the context of narrowly defined social service agency mandates that may limit holistic care for the diverse needs of the mother and child as a unit (Poole \& Urquhart, 2010). 
Notably, mothers with problematic substance use are also more likely to experience child-related difficulties. Prenatal drug exposure during pregnancy has been linked to many poor birth and infant outcomes, including prematurity, low birth weight, irritable temperament, and cognitive and behavioural problems, with specific sequalae differing depending on substance, timing and dosage of exposure (Behnke et al., 2013; Buckingham-Howe, Berger, Scaletti \& Black, 2013; Mayes \& Fahy, 2001; Neger \& Prinz, 2015; Schempf, 2007). As mothers with problematic substance use are likely experiencing many other life stressors, having a child with greater tendencies toward cognitive and behavioral challenges may add significantly to parenting stress. When children show greater dysregulation, mothers may be less able to cope with these difficulties, leading to negative relationship dynamics that again exacerbate parenting stress. For example, in their longitudinal study of children with developmental delays, Neece and colleagues (2012) found a transactional relationship in which high parenting stress led to worsening behavioral issues, which in turn contributed to worsening parenting stress over early childhood. As such, a mother may find herself in an intensifying cycle of increased parenting stress and behavioral difficulties with their child.

High levels of personal distress are also of concern in this population. Mothers with problematic substance use are more likely to experience poverty, which is linked to clinical levels of parenting stress (Steele et al., 2016). Lack of social support is likewise an issue as women who have experienced neglectful or abusive parenting themselves are unable or unwilling to access support from their families when beginning their own (Finkelstein, 1994). Maternal psychopathology is common among mothers with problematic substance use, including high levels of depression and anxiety symptoms that are also positively associated with parenting stress (Leigh \& Milgrom, 2008; Sheinkopf et al., 2005; Steele et al., 2016; Williford et al., 2007). 
The impact of mental health on parenting stress may be particularly severe in cases where posttraumatic stress disorder symptoms intensify stress reactivity or where emotional dysregulation is a concern (Ammerman et al., 2013; Eisenberg \& Spinrad, 2004; Neger \& Prinz, 2015). Significant stress-related vulnerability also arises from substance use in and of itself. Evidence now highlights the role of alcohol, nicotine and other substances (e.g., cocaine) in activating the HPA axis to secrete cortisol (a critical stress hormone) (Lovallo, 2006; Mello, 2010). Mothers with problematic substance use thus experience heightened reactivity to life and parenting stressors, in part due to their exposure to substances (Rutherford et al., 2013). Regulating stress may also be undermined by disruptions to stress-related neural circuitry as a result of substanceexposure and substance-related cravings (Rutherford et al., 2013; Sinha, 2008). For mothers experiencing the dual challenges of mental health difficulties and problematic substance use, personal resources may need to be directed to managing these difficulties, leaving fewer resources available for parenting and thereby increasing perceptions of parenting stress (Matusiewicz, Macatee, Guller \& Lejuez, 2013). Taken together, multiple risks accumulate to increase risk for parenting stress in mothers with problematic substance use. However, clinical levels of parenting stress are not experienced by all mothers with problematic substance use (Kelley, 1998; Liles et al., 2012). As such, it is critical to explore individual factors that may support resilience.

\subsection{Maternal Executive Function and Parenting Stress}

While environmental and mental health-related influences on parenting stress have been the subject of considerable research, the association between maternal cognitive factors and parenting stress has received scant attention. Executive functions is an umbrella term for multiple neurocognitive abilities involved in conscious control of feelings, cognitions and behaviours that 
contribute to planning, initiation, self-monitoring and regulation (Monn, Narayan, Kalstabakken, Schubert \& Masten, 2017; Stuss, 2011). According to Friedman and Miyake (2017), executive functions are high-level cognitive mechanisms that allow individuals to regulate their behaviors and thoughts in service of their goals. They identify three basic executive functions: updating processes, related to monitoring and updating working memory; shifting, involving flexibly switching between cognitive tasks or mental sets; and inhibition, involving deliberate overriding of existing dominant responses (Miyake \& Friedman, 2000). These functions are typically correlated, activating specific but connected neural regions and are also significantly associated with individual differences in brain volume and connectivity (Friedman \& Miyake, 2017).

Greater executive function difficulties can be conceptualized to heighten perceived parenting stress and household chaos via impacts on three general stress-related processes: stress exposure, reactivity and recovery (William, Suchy \& Rau, 2009). Regarding stress exposure, weaknesses in executive functions increase the probability of an individual coming in contact with stressful events, as they may have more difficulties staying on task, making decisions, organizing and planning (Williams, Suchy, \& Rau, 2009). In the context of motherhood, there can be little doubt that planning, organizing and decision-making abilities are frequently required to establish a lower stress, less chaotic family environment. According to Barrett and Fleming (2011), many maternal behaviors are highly influenced by executive functions:

Processes such as cognitive flexibility, working memory and attentional control are fundamental components of mothering and key to maternal sensitivity. A mother must have the attentional command to focus on her infant which allows her to be sensitive to infant needs... She must also have the cognitive flexibility to switch her attention efficiently across many situational demands, in highly stimulating environments. She 
must also maintain and manipulate information in her working memory to plan and guide mother-infant interaction and infant care (p. 369).

Thus, when challenges with updating, shifting and inhibition occur in a parenting context, mothers may experience greater difficulty responding to their child's needs and managing their child's distress, which in turn increases the likelihood of more demanding child-caregiver scenarios and greater parenting stress (Crandall et al., 2015). Once exposed to stressful caregiving events, individuals with poorer executive functions show higher reactivity to these events, including greater subjective distress and physical arousal (i.e., low resting heart rate variability and release of stress hormones like cortisol) (Hansen, Johnsen \& Thayer, 2003; Johnson, Hansen, Murison \& Thayer, 2002; Lazarus \& Folkman,1984). In a parenting context, this may mean that mothers with lower executive function performance may have stronger emotional and physiological reactions to negative child behaviors (e.g., crying, tantrums) or difficult caregiving situations. In turn, these stronger emotions (i.e., anger) may magnify parenting stress and levels of household chaos (Deater-Deckard, Wang, Chen, \& Bell, 2012). For example, maternal depression has been associated with both parenting stress and reduced executive function (Channon \& Green, 1999; Milgrom \& McCloud, 1996). Finally, executive functions may be associated with parenting stress recovery as lower shifting and inhibition functions are associated with depressive rumination and prolonged activation of the stress system (Davis \& Nolen-Hoeksema, 2000; Whitmer \& Banich, 2007). As such, mothers with lower executive functions may recover more slowly after stressful experiences, which may heighten parenting stress and household chaos. Overall, as stress exposure, reactivity and recovery all play a critical role in parenting, reduced maternal executive functions may impact parenting stress and 
household chaos via its influence on these stress-related processes (Williams, Suchy, \& Rau, 2009).

Executive functions may be even more salient for parenting stress in mothers with problematic substance use. Research highlights executive functions as a key predictor of substance use initiation and severity in adolescence (Aytaclar, Tarter, Kirisci \& Lu, 1999; Pentz et al., 2015, Peeters et al., 2015; Tarter et al., 2003). This may be because individuals with lower inhibition and updating capacities are more likely to focus on immediately rewarding experiences rather than long-term goals, leading to more impulsive, unplanned responses to substance use in early life (Grenard et al., 2008). Chronic alcohol, marijuana, and cocaine use are associated with reduced executive functions, with early onset of use typically predicting greater difficulties (Brown \& Tapert, 2004; Crean, Crane \& Mason, 2011; Madoz-Gúrpide et al., 2011). Reduced executive function may be further magnified by concurrent mental health disorders, that are themselves associated with mental health impairment, including depression and post-traumatic stress disorder (Flaks et al., 2014; Mozzambani et al., 2017; Snyder, 2013). Despite heightened risk for both lower executive function and greater parenting stress in the context of maternal problematic substance use, no known studies have examined this relation (Rutherford et al., 2013).

Limited research with parents of children with behavioural challenges may support theorizing about the relation between executive functions and parenting stress in mothers with problematic substances use. In a sample of mothers from diverse socio-economic backgrounds, Deater-Deckard et al. (2012) found that lower maternal performance on a range of executive functions measures combined into a composite score was associated with increased household chaos (i.e., DH parenting stress), but only in the context of low SES. No known studies, 
however, have examined the relation between executive functions and perceived parenting stress using the P-C-R model. Further, research has examined executive functions as a single construct, without examining potential differences that updating, inhibition and shifting may have on parenting stress (Friedman \& Miyake, 2017).

\subsection{The Current Study}

This study was designed to address limations regarding (1) the lack of data on the relation between executive funtions and parenting stress in mothers with problematic substance use; (2) the relative strength of the associations between parenting stress and three executive functions (updating, inhibition, and shifting), and (3) the strength of the association between executive functions and parenting stress defined using both P-C-R and DH conceptualizations of parenting stress.

\section{METHODS}

\subsection{Participants}

Participants were recruited from treatment programs for mothers with problematic substance use in Ontario. Research partnerships with treatment programs had been previously established in the context of a provincial evaluation of these programs (see Milligan, Usher, \& Urbanoski, 2016). Treatment programs were contacted by email to determine their willingness to support recruitment of their clients (e.g., share study information verbally and post recruitment posters) and to provide space for data collection. Programs were provided with an overview of

the study, as well as an informed consent agreement outlining the known risks and requirements of acting as a participating agency. The voluntary nature of participation for programs and individual participants was emphasized. 
Eight of eleven programs contacted agreed to participate. Of the three programs that decided not to participate, lack of available clients meeting eligibility criteria and lack of availability due to other organizational obligations were cited as the primary reasons. Programs were located in geographically diverse areas, including urban and rural sites. To be eligible for the study women had to: (1) be enrolled in a substance use treatment program; (2) have at least one child aged 3 years or under; and (3) be currently parenting or have a minimum of weekly access to their child if their child was in the care of a child welfare agency.

Sixty-five women agreed to participate in the study (Mean Age $=30, S D=5.5$ years). One participant was removed from data analysis due to child age not meeting inclusion criteria $(>4$ years of age). Participant demographics are presented in Table 1. In addition to these characteristics, the majority of women reported at least one indicator of low socio-economic status, including $61 \%$ reporting food insecurity, $30 \%$ reporting housing insecurity and $46 \%$ reporting difficulty paying for utilities. While $72 \%$ of women reported current involvement with child protection services; $80 \%$ reported that their child was in their care on a full-time basis. 
Table 1

Participant Demographic Characteristics

\begin{tabular}{|c|c|c|}
\hline Characteristic & $\mathbf{N}$ & $\%$ \\
\hline \multicolumn{3}{|l|}{ Age } \\
\hline$\overline{19-25}$ & 14 & 21.5 \\
\hline $26-34$ & 40 & 61.5 \\
\hline $35-44$ & 10 & 15.4 \\
\hline $45+$ & 1 & 1.5 \\
\hline \multicolumn{3}{|l|}{ Ethnicity } \\
\hline White & 50 & 76.9 \\
\hline Black & 3 & 4.6 \\
\hline Aboriginal & 5 & 7.7 \\
\hline Other & 7 & 10.7 \\
\hline \multicolumn{3}{|l|}{ Marital Status } \\
\hline Single & 31 & 47.7 \\
\hline Committed relationship & 24 & 36.9 \\
\hline Married & 4 & 6.2 \\
\hline Divorced/Separated & 2 & 3.1 \\
\hline Widowed & 2 & 3.1 \\
\hline \multicolumn{3}{|l|}{ Education } \\
\hline Some high school & 19 & 29.2 \\
\hline High School diploma & 14 & 21.5 \\
\hline Some College & 26 & 40.0 \\
\hline Some University & 6 & 9.2 \\
\hline \multicolumn{3}{|l|}{ Employment } \\
\hline Employed & 7 & 10.8 \\
\hline Student & 2 & 3.1 \\
\hline Homemaker & 24 & 36.9 \\
\hline Unemployed & 32 & 49.2 \\
\hline \multicolumn{3}{|l|}{ Number of children } \\
\hline 1 & 18 & 27.7 \\
\hline 2 & 24 & 36.9 \\
\hline 3 & 12 & 18.5 \\
\hline 4 or more & 11 & 17.0 \\
\hline
\end{tabular}

Note: $N=64$.

The majority of participants $(72 \%)$ reported experiencing substance use-related symptoms (e.g., abuse, dependence) in the previous year. In terms of mood, $48.4 \%$ reported mild 
depressive symptoms, whereas $25.8 \%$ reported depressive symptoms in the moderate to extremely severe range. Participating mothers had been involved in substance use treatment at the location of data collection for a mean of 18.8 months ( $S D=19.0$; Range: 64 months).

\subsection{Procedure}

A team of four to nine researchers (i.e., undergraduate and graduate students, doctoral level researchers) travelled to each participating substance use program site. To facilitate data collection and enhance feasibility of attendance for participants, data collection was completed during a time when mothers regularly attended group treatment. A series of data collection stations was set up that participants rotated through, with the order of tasks randomized. Following informed consent procedures, mothers were provided with a participant folder of questionnaires to complete in a group room, which included substance use, mental health and parenting stress-related measures. A researcher was present in this group room at all times to answer questions about the questionnaires and ensure that participants' privacy was maintained. While questionnaires were being completed, participants were individually asked to accompany another research assistant to additional stations where executive function tasks were administered in a private room by a trained researcher. Data collection was completed within a two-hour period with groups of two to six women at a time. Childcare was provided and participants were given a $\$ 40$ grocery store gift card for their participation.

To support confidentiality, all data forms from data collection were identifiable by participant number only, except informed consent forms that were stored in a separate location at the Child Self-Regulation Lab at Ryerson University. Research ethics approval was granted for all procedures by the Ryerson Research Ethics Board. 


\subsection{Measures}

2.3.1 Perceived Parenting Stress: P-C-R model. Parenting stress was evaluated using the Parenting Stress Index Short Form, fourth edition (PSI-SF-4). As the most commonly used measure of parenting stress, the original Parenting Stress Index (PSI; Abidin,1990) self-report questionnaire includes 120 items, which has been reduced to 36 items in the short form version (Abiden, 2012; Deater-Deckard, Chen, \& El-Mallah, 2013). The short form is designed to evaluate a P-C-R formulation of parentings stress using three domains of perceived stress that may impact the child-parent relationship: 1) parental distress, 2) having a difficult child, and 3) parent-child dysfunctional interactions that are combined into a total stress scale (Abidin, 1990). The total stress scale shows excellent internal consistency $(\alpha=.90-.92)$ and good test-retest reliability $(\alpha=.77-.78)$ (Barroso et al., 2016). The measure has been validated for marginalized/high-risk parents with a moderate convergent validity across related measures (Barroso et al., 2016). Higher scores on the PSI-SF are associated with a number of factors known to undermine the parent-child system, including higher levels of difficult child temperaments, single parenthood and low social support, lower socio-economic status, maternal adverse childhood experiences and maternal psychopathology (Chen, Tyler, Whitbeck, \& Hoyt, 2004; Misri, Reebye, Milis, \& Shah, 2006; Sheinkopf et al., 2005; Steele et al., 2016; Williford et al., 2007). For this study, the Total Stress percentile score of the PSI-SF-4 was used as a measure of self-perceived parenting stress.

2.3.2 Household Chaos: DH Model. The Confusion, Hubbub and Order Scale (CHAOS) was used to assess household chaos as an indicator of parenting stress consistent with a Daily Hassles approach. The CHAOS is a fifteen question self-report measure that evaluates behavioral and environmental indicators of the state of disorder (e.g. crowding, noise, disarray, 
unpredictable setting, lack of routine) in the household (e.g. "it's a real zoo in our home") (Matheny Jr., Wachs, Ludwig, \& Phillips, 1995). It is scored on a Likert scale from 1 to 4 with higher scores indicative of greater confusion and environmental stress in the home environment. This measure has good internal consistency $(\alpha=0.79)$ and high test-retest stability overtime (Matheny Jr. et al., 1995). This measure also shows good construct validity, predicting indicators of environmental demands (e.g., number of siblings, noise ratings) and parental behaviours (e.g., verbal interference, physical interference, negative responding) (Matheny Jr. et al., 1995; Valiente, Lemergy-Chalfant \& Reiser, 2007). In a population of European mothers with children of preschool age, this measure moderately correlates with the PSI-SF-4 $(r=.46, p<.01)$ (Dumas et al., 2005).

2.3.3 Updating. Updating functions (i.e., working memory) were assessed using the Backward Digit Span task of the Wechsler Adult Intelligence Scale: 4th Edition (WAIS IV; Wechsler, Coalson \& Raiford, 2008). The Backward Digit Span is a sub-task within the larger WAIS Digit Span Task. It provides increasingly longer lists of numbers, requesting the participant to verbally report the list back from the end to the beginning. Psychometrically, the complete WAIS Digit Span Task shows good internal consistency (i.e., greater than $\alpha=0.89$ ) for all age groups (Wechsler et al., 2008). With regards to construct validity, confirmatory factor analysis of the WAIS IV identifies a five-factor solution with an updating (i.e., working memory) factor anchored by the Digit Span Task $(\mathrm{CFI}=0.95, \mathrm{RMSEA}=0.60)($ Holdnack, Zhou, Larrabee, Millis, \& Salthouse, 2011). For this analysis, scaled scores related to a greater number of accurately completed lists was used as the indicator of better participant updating capacity. 
2.3.4 Shifting. This executive function was evaluated using the Delis-Kaplan Executive Function System Trail-Making Task, which asks participants to flexibly shift between numbered and alphabetical lists (D-KEFS; Delis, Kaplan \& Kramer, 2001). The Trail-Making Task shows split-half reliability ranging from moderate to good $(0.53-0.80)$ across age groups, but lower test-retest reliability $(0.32-0.77)$ indicating potential practice effects (Delis et al., 2001). Validity studies of the D-KEFS test battery indicate good evidence of convergent validity with other tests of executive function, and reasonable sensitivity in identifying clinically significant dysfunction such as brain lesions, head injury, and substance-related impairments (e.g., Korsakoff's syndrome, chronic alcoholism) (Homack, Lee \& Riccio, 2005). In terms of construct validity, Latzman \& Markon (2010) have found a three-factor model for the DKEFs with the Trail-Making Task showing significant loading on a shifting (i.e., flexibility) factor. For this analysis, the number-letter switching score controlling for combined number sequencing and letter sequencing was used as the indicator of participant shifting capacity, with higher scores indicating better performance on the task.

2.3.5 Inhibition. A Stop Signal Task was presented to women using Presentation software (Neurobehavioural Systems) following the task description provided by Patterson and colleagues (2016). Only the emotional neutral condition of this task was used for this study. Participants were presented with a left or right facing arrow on the screen and asked to select the same arrow on their keyboard as quickly as possible; however, they were asked to inhibit this response when presented with a tone. Participants wore headphones (SONY MDR-ZX110). A practice session with 30 trials was followed by the test session, which included 38 'go' trials and 16 'stop' trials presented in randomized order. The total number of errors on 'stop' trials was 
used to indicate increased difficulties with inhibition, with lower numbers of errors indicating better performance on the task.

2.3.6 Maternal Demographic Factors. A survey was developed by the research team to assess key demographic information for all participants, including age, ethnicity, marital status, employment status, pregnancy status, length of substance-use treatment, number of children given birth to, and education level. Participants were also asked to briefly describe past/current involvement with child welfare. Finally, on this form socio-economic status was assessed using proxy indicators of poverty (SES; Antwi-Boasiako et al., 2016). Specifically, participants were asked to answer questions on a 5-point Likert scale related to food security (e.g., "during the past six months, how often have you worried about being able to pay for food?'), housing security (e.g., "during the past six months, how often have you worried about being able to pay your rent/mortgage?") and their ability to pay their utilities (e.g., "during the past six month, how often have you worried about being able to pay for your utilities?"). Responses to these three questions were totaled as composite measure of SES (Combined SES) with higher scores indicating lower SES.

2.3.7 Maternal Substance Use. Substance use was assessed via self-report using the 16item Substance Use Problem Scale of the Global Appraisal of Individual Needs Assessment System (GAIN-SS; Dennis et al., 2008). Participants were asked to indicate whether or not they have engaged in substance-related behaviours that are indicative of a substance-use disorder (e.g., "you tried to hide that you were using alcohol or drugs"; your alcohol or drug use caused you to have repeated problems with the law"). This measure can be used dimensionally, with greater affirmative responses suggesting higher levels of substance-related impairment (Dennis et al., 2003). Each item is scored with a 2 if the behaviour occurred within the past month, 
scored with a 1 if the behaviour occurred between 2 and 12 months ago, and scored with a 0 if the behaviour occurred longer than 12 months ago or not ever. The GAIN-SS is widely used within the substance use research community, showing high rates of internal consistency ( $\alpha=$ $0.90)$ and good test- retest reliability $(r=0.70-0.81)$ (Dennis et al., 2003). Moreover, this scale shows a strongly unidimensional factor structure based on confirmatory factor analysis (CFI = 0.965, RMSEA $=0.056$ ) (Stucky, Edelen \& Ramchand, 2014). Higher factor loading (range of $0.73-0.81)$ supports good construct validity related to addiction severity and the impact of addiction on daily functioning (Stucky et al., 2014).

2.3.8 Maternal Depression. Given the association between maternal depression and parenting stress (Milgrom \& McCloud, 1996) and its associations with reduced executive function (Channon \& Green, 1999), maternal depression status was assessed using the Depression Anxiety Stress Scales - short form Depression Sub-Scale (DASS-21, Lovibond \& Lovibond, 1995). The DASS-21 is a 21 item self-report measure based on the original 42 -item DASS (Lovibond \& Lovibond, 1995). It includes three sub-scales to separately assess clinical symptoms of depression, anxiety and stress. Internal consistency for all three sub-scales is strong ( $\alpha=0.91$ for depression; $\alpha=0.80$ for anxiety; $\alpha=0.84$ for stress) (Sinclair et al., 2012). Exploratory factor analysis of the DASS-21 is consistent with a three-factor solution based on the three symptom sub-scales, with generally high mean loadings for individual items (Antony, Bieling, Cox, Enns \& Swinson, 1998). The DASS-21 Depression Sub-Scale has recently been validated for substance use disorder patients, with satisfactory levels of sensitivity (78 - 89\%) and specificity $(71-76 \%)$ for identification of depressive disorders, when compared to diagnoses from the Mini International Neuropsychiatric Interview (MINI) (Beaufort, De Weert-Van Oene, Buwalda, de Leeuw, \& Goudriaan, 2017). 


\subsection{Hypotheses}

It was hypothesized that measures of the three executive functions (shifting, updating, inhibition) would contribute significant variance over and above key covariates to two outcomes of parenting stress, perceived parenting stress (consistent with a P-C-R model of parenting stress) and household chaos (consistent with a DH model of parenting stress). Thus, lower maternal performance on updating, shifting and inhibition tasks would be associated with significantly higher parenting stress in mothers with problematic substance use. Given the absence of previous research examining individual executive functions and parenting stress, analyses into the relative contributions of each were exploratory and no specific hypotheses were made.

\subsection{Statistical Analyses}

All independent and dependent variables were reviewed for normality using P-P Plots and some minimal skewing was identified. As such, medians and interquartile ranges were calculated and reported for all measures. Non-parametric correlational analyses using Spearman's rho were also completed and reported. One-step multiple linear regression was completed for the outcomes of perceived parenting stress (i.e., the PSI-SF-4 Total Stress measure) and household chaos (i.e., CHAOs measure) using robust regression with 5000 bootstrapped samples (bias corrected and accelerated). Assumptions regarding the generalizability of the regression models were fully tested and are reported in the results section. Covariates were included in models based on correlations with the data, and existing trends in the literature. All models were constructed using the Statistical Package for the Social Sciences (SPSS version 22). 


\section{RESULTS}

3.1 Descriptive Statistics. Medians and interquartile ranges were examined for all measures used in the analysis (Table 2). As study measures were skewed (i.e., non-normal), comparison to a normative sample for their clinical significance should be assessed with caution.

Table 2

Descriptive Statistics for Executive Functions and Parenting Stress Measures

\begin{tabular}{lcc}
\hline Measure & Median & Interquartile Range \\
\hline Executive Functions & & \\
Backward Digit Span Task & 8 & 2.00 \\
Trail-Making Task & 9 & 3.00 \\
Stop Signal Task & 5 & 4.00 \\
Parenting Outcomes & & \\
PSI-SF-4 Total Stress & 55 & 43.00 \\
CHAOS & 27 & 9.75 \\
Covariates & & \\
GAIN-SS & 9.5 & 13.75 \\
DASS-21 Depression & 6 & 9.5 \\
Combined SES & 4.5 & 2.75 \\
Age of Youngest Child (in years) & 1 & 2.00 \\
\hline
\end{tabular}

Note: $\mathrm{N}=64$. Reported median scores for Backward Digit Span and Trail-Making Tasks are standard scores, and scores for PSI-SF-4 Total Stress is a percentile score. All other reported scores are raw scores.

\subsection{Correlations between Executive Function and Parenting Stress Measures}

Two-tailed Spearman's rho correlations among measures of executive function, perceived parenting stress and household chaos were examined (Table 3). No significant correlations were found between measures of executive functions (i.e., the Backward Digit Span, Trail-Making and Stop Signal Tasks). Given the lack of consistent correlations between executive function measures, each executive function task was examined individually in the analyses. The two parenting stress measures (PSI-SF-4 Total Stress and CHAOS) were moderately correlated; however, given our interest in understanding relations between executive functions and each of 
these measures of parenting stress, each outcome was examined separately in subsequent analyses.

Correlations were also analyzed for potential covariates in the analysis. Both the DASS21 Depression Sub-Scale and the Combined SES measure were found to significantly correlate with the CHAOS measure of parenting stress, whereas DASS-21 Depression Sub-Scale and Age of Youngest Child significantly correlated with the PSI-SF-4 Total Stress. The GAIN-SS was not found to correlate with any study measures and as such, was not included as a covariate in the analyses. Where significant relations were identified, variables were controlled for in further analyses. Findings in the literature were also considered in the selection of covariates.

Table 3

Spearman's rho Correlations $\left(r_{s}\right)$ for Executive Function and Parenting Stress Measures

$\begin{array}{lllllllll}1 & 2 & 3 & 4 & 5 & 6 & 7 & 8 & 9\end{array}$

1. Backward Digit Span Task

2. Trail-Making Task $-.061 \quad-$

3. Stop Signal Task $.284 \quad-.040 \quad-$

4. PSI-SF-4 Total Stress

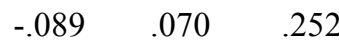

5. CHAOS $\begin{array}{lllll}.058 & .098 & .256 & .505 * *\end{array}$

6. DASS-21 Depression Sub$\begin{array}{llllll}.046 & -.047 & .382 * * & .634 * & .499 * * & -\end{array}$

Scale

7. Combined SES

$.196 \quad .012 \quad .016$

8. Age of Youngest Child

.14

9. GAIN-SS

.065

$-.061$

.18

.22

$.374 * * \quad .077$

$.377 * * \quad .153$

.205

$.096 \quad-.128$

.061

.12

$.072 \quad-.013 \quad .151$

Note: $N=64$. Significant two-tailed: ${ }^{*} \mathrm{p}<.05 ;{ }^{*} \mathrm{p}<.001$. 


\subsection{Executive Functions, Perceived Parenting Stress and Household Chaos}

Two multiple regression models were examined to test hypotheses related to outcomes of perceived parenting stress and household chaos. Assumptions regarding the generalizability of the regression models were fully tested. No outliers were identified in the dataset based on a diagnostic of standardized residuals. Independence of errors was confirmed based on DurbinWatson test values close to 2 for all variables (Field, 2009). The assumption of multicollinearity was satisfied as all VIF values were below 10, with tolerance above 0.2 (Field, 2009). Finally, based on a review of scatter plots for predicted error versus residual error, no predictors violated assumptions of homoscedasticity. Residual error plots indicated minimal skewing for both dependent variables, indicating non-normality. As such, both the PSI-SF-4 Total Stress and CHAOS outcome variables were log-transformed and analyzed. Log-transformation of the PSISF-4 Total Stress variable further reduced normal distribution of errors. Given this, and that skewing was minimal, this data was not transformed in the regression results reported below. For CHAOS, log-transformation led to the assumption of normal distribution of errors being fully met. As such, the log-transformed data was used for the regression analysis.

For the first model, PSI-SF-4 Total Stress was regressed on the three executive functions. Thus, three predictor variables were inputted: 1) Backward Digit Span Task; 2) Trail-Making Task and 3) Stop Signal Task, while the outcome variable was PSI-SF-4 Total Stress (Table 4). Age of Youngest Child was entered in the same regression step as a covariate, as this measure was correlated with PSI-SF-4 Total Stress. The inclusion of this covariate was consistent with research identifying child age as a predictor of P-C-R parenting stress (Abidin, 1990; Neece et al., 2012; Williford et al., 2007). Although Combined SES was not correlated with PSI-SF-4 Total Stress, it was also included as a covariate based on findings in the literature indicating a 
strong role for SES status in influencing parenting stress (Abidin, 1990; Reitman, Currier, \& Stickle, 2002; Whiteside-Mansell et al., 2007). Depression was not entered as a covariate as maternal psychopathology is a substantial part of the Parental Distress Sub-Scale of the PSI-SF (Abidin, 1990). In the bootstrapped model, poorer performance (i.e., more errors) on the Stop Signal Task $(B=3.47, S E=1.46, p=.022,95 \%$ CI $[.328,5.926])$ led to significant increases in PSI-SF-4 Total Stress. As well, poorer performance (i.e., lower scores) on the Backward Digit Span Task led to significant increases in PSI-SF-4 Total Stress $(B=-3.74, S E=1.75, p=.041$, 95\% CI $[-7.035, .104])$. Performance on the Trail-Making Task did not significantly impact PSISF-4 Total Stress. However, covariates of higher Age of Youngest Child $(B=8.67, S E=3.25, p$ $=.010,95 \% \mathrm{CI}[2.254,14.499])$ and higher scores on Combined SES (i.e., lower socio-economic status, $B=3.48, S E=1.30, p=.004,95 \%$ CI $[1.231,7.029])$ were associated with significant increases in PSI-SF-4 Total Stress. In this model, 31.8\% (Adjusted R Square) of the variance in perceived parenting stress was explained by these predictors $(F(5,42)=5.38, p=.001)$.

Table 4

Regression of PSI-SF-4 Total Stress on Updating, Shifting and Inhibition Functions

\begin{tabular}{lrrrrr}
\hline & Coefficient & $S E$ & $\beta$ & $t$ & $p$ \\
\cline { 2 - 6 } Backward Digit Span Task & -3.735 & 1.754 & -.267 & -2.130 & .039 \\
Trail-Making Task & 1.745 & 1.347 & .157 & 1.296 & .202 \\
Stop Signal Task & 3.472 & 1.263 & .354 & 2.748 & .009 \\
Combined SES & 3.480 & 1.337 & .319 & 2.603 & .013 \\
Age of Youngest Child & 8.666 & 3.211 & .335 & 2.699 & .010 \\
\hline & Bootstrap Estimate & & $95 \%$ Confidence \\
\cline { 2 - 6 } & Estimate & \multicolumn{2}{c}{ Interval } \\
\hline Backward Digit Span Task & -3.735 & 1.862 & .041 & -7.035 & .104 \\
Trail-Making Task & 1.745 & 1.152 & .134 & -.735 & 3.878 \\
Stop Signal Task & 3.472 & 1.464 & .022 & .328 & 5.926 \\
Combined SES & 3.480 & 1.303 & .004 & 1.231 & 7.029 \\
Age of Youngest Child & 8.666 & 3.246 & .010 & 2.254 & 14.499 \\
\hline
\end{tabular}

Note: $N=47$. 
In the second model, Log CHAOS was regressed on the three executive functions: 1) Backward Digit Span Task; 2) Trail-Making Task and 3) Stop Signal Task (Table 5). Covariates of Combined SES and DASS-21 Depression Sub-Scale were also entered in the same regression step given the significant correlation between these factors and CHAOS, as well as support in the literature for significant associations between these variables and household chaos (Hur, Buettner, \& Jeon, 2015; Shelleby et al., 2014; Evans, Eckenrode, \& Marcynyszyn, 2010). In this model, performance on the three executive function tasks did not significantly contribute to the CHAOS score. However, higher depressive symptoms on the DASS-21 Depression Sub-Scale ( $B$ $=.004, S E=.001, p=.003,95 \% \mathrm{CI}[.002, .007])$ and lower Combined SES $(B=.020, S E=.007$, $p=.005,95 \% \mathrm{CI}[.005, .039])$ were both associated with significant increases in the CHAOS score. In this model, 34.6\% (Adjusted R Square) of the variance in household chaos was explained by these predictors $(\mathrm{F}(5,43)=6.08, \mathrm{p}<.001)$.

Table 5

Regression of Log CHAOS on Updating, Shifting and Inhibition Functions

\begin{tabular}{lrrrrr}
\hline & Coefficient & $S E$ & $\beta$ & $t$ & $p$ \\
\cline { 2 - 6 } Backward Digit Span Task &. .001 & .007 & -.017 & -.142 & .888 \\
Trail-Making Task & .008 & .006 & .166 & 1.420 & .163 \\
Stop Signal Task & .011 & .005 & .245 & 1.929 & .060 \\
Combined SES & .020 & .006 & .413 & 3.485 & .001 \\
DASS 21 Depression Sub-Scale & .004 & .001 & .379 & 3.125 & .003 \\
\hline & \multicolumn{2}{c}{ Bootstrap Estimate } & \multicolumn{3}{c}{$95 \%$ Confidence } \\
& \multicolumn{2}{c}{ Interval } \\
\cline { 2 - 6 } & Estimate & $S E$ & $p$ & Lower & Upper \\
Backward Digit Span Task & -.001 & .008 & .891 & -.018 & .015 \\
Trail-Making Task & .008 & .006 & .153 & -.003 & .021 \\
Stop Signal Task & .011 & .006 & .072 & .001 & .019 \\
Combined SES & .020 & .007 & .005 & .005 & .039 \\
DASS 21 Depression Sub-Scale & .004 & .001 & .003 & .002 & .007 \\
\hline
\end{tabular}

Note: $N=48$. 


\section{Discussion}

There is a growing recognition of the important role maternal executive functions play in parenting outcomes, including parenting stress. Despite increased prevalence of challenges with executive functions and parenting stress in mothers with problematic substance use, no studies had explored this relation. Further, methodological limitations exist in the current literature, namely a lack of specificity in terms of the contribution of different executive functions to conceptualizations of various parenting outcomes. The present study sought to address these issues.

Findings of the current study support the presence of a significant relation between executive functions and parenting stress in mothers with problematic substance use and highlight the need to explore the relative strength of the relation with attention to different executive functions (i.e., updating, inhibition, shifting) and conceptualizations of parenting stress (P-C-R and $\mathrm{DH}$ theories). In particular, relations were identified between inhibition and updating functions for our model of perceived parenting stress, but no effect of executive functions was identified when modeling household chaos. Thus, there was heterogeneity in the findings based on type of executive function and stress conceptualization utilized.

\subsection{Executive Functions and Parenting Stress: The Need for Executive Function}

Specificity. The current study found a significant relation between executive function and

perceived parenting stress (P-C-R approach). Specifically, significant relations were found between lower inhibition performance and increased perceived parenting stress as well as between lower updating performance and increased perceived parenting stress. Notably, this was the first study of its kind to identify an association between maternal executive function and perceived parenting stress based on a P-C-R Model. 
Yet, in this study, individual differences in executive function challenges were not associated with household chaos (i.e., DH approach). These results for the household chaos model were inconsistent with previous research showing that a composite score of executive functions (including shifting, inhibition, working memory, planning and problem-solving) was related to household chaos, but only under conditions of low SES (similar to the current sample) (Deater-Deckard et al., 2012). This discrepancy in results may reflect a lack of power in the current study, recognizing that the relation between inhibition and household chaos was trending toward significance $(\mathrm{p}=0.072)$. It is also notable that Deater-Deckard and colleagues administered a number of complex executive function tasks (Wisconsin Card Sorting Test, Tower of Hanoi). These complex tasks may have been experienced as more difficult, or tapped into higher-order executive functions such as planning and/or problem-solving. It is possible that this complexity may have lead to greater variability in executive function performance, which may in turn have increased the sensitivity to detect effects.

There has been ongoing debate regarding whether or not executive functions should be viewed as a unitary construct with one underlying mechanism or a set of distinct, loosely related processes (Miyake, Friedman, Rettinger, Shah, \& Hegarty, 2001; Stuss \& Alexander, 2000). Recently, many in the field have identified a middle ground, viewing executive functions in terms of both unity and diversity of function (Banich, 2009; Friedman et al., 2008). This approach recognizes the domain-general activation of the frontal-parietal lobes across tasks, while acknowledging that performance on different tasks shows limited association within individuals (Friedman \& Miyake, 2017). Indeed, correlations between different executive function tasks are typically low ( $\mathrm{r}=.4$ or less, as seen in the present study) and often not statistically significant (Miyake et al., 2000). Evidence continues to accumulate that distinct 
functions of updating, inhibition and shifting contribute to more complex, 'higher' executive function processes such as planning and goal-setting (Friedman \& Miyake, 2017). A notable strength of this study was that all three of these executive functions were investigated in terms of their influence on perceived parenting stress and household chaos, as to-date few studies on executive functions and parenting have included all three executive functions or examined parenting stress using these two conceptualizations. By including a measure of each of the three functions, the influence of separate executive functions on parenting stress could be further analyzed.

The specificity of different executive functions has been documented in the context of other parenting outcomes beyond parenting stress. Studies suggest that inhibition may be important in supporting mothers to impede negative behavioural responses to their child (e.g., angry discipline) as mothers with better inhibition capacity show more sensitive parenting when moving from enjoyable to difficult/stressful parenting situations (Sturge-Apple, Jones, and Suor, 2016). Similarly, Atkinson and colleagues (2009) also found that mothers who respond less sensitively to their infants show lower capacity for inhibiting dominant responses on emotional Stroop tasks. Maternal executive functions may be particularly relevant under stressful environmental conditions, such as poverty or precarious employment. In their comparison of mothers from disadvantaged backgrounds who had, and had not engaged in child neglect, Azar and colleagues (2017) found that performance on the Wisconsin Card Sorting Test (a measure of inhibition and shifting) significantly predicted child neglect. Similarly, in their study Shaffer and Obradovic (2016) found that a relation between greater SES and maternal sensitivity was partially mediated by inhibition, further supporting the notion that inhibition at a minimum is critical to maternal sensitivity in cases where the parent is already experiencing significant life 
stress. Such findings are in keeping with recent work by Monn and colleagues (2017). Using a sample of 94 homeless (i.e., high-risk) mothers, they found that planning ability (a higher-order function linked to inhibition) was significantly related to harsh parenting, but only for mothers with higher levels of perceived general stress. Indeed, these results are consistent with our findings that inhibition may relate to levels of perceived parenting stress, particularly for highrisk, high-stress samples such as mothers with problematic substance use.

Similar to the positive relation between maternal updating and perceived parenting stress in the current study, updating (i.e., working memory) has been found to partially mediate a relationship between higher SES and maternal scaffolding behaviours (Obradovic et al., 2017). It also predicts greater time spent between mother and child, lower parental reflective functioning, and more maternal interest and curiosity in child mental states (Chico et al., 2014; Håkansson, Söderström, Watten, Skårderud \& Glenne Øie., Rutherford et al., 2018). With regards to maternal sensitivity, Deater-Deckard et al. (2010) found that increased maternal difficulties with updating were significantly associated with harsh and overly reactive parenting at times when children showed challenging/difficult behaviours. As well, in their path analysis study, Gonzalez, Jenkins, Steiner, \& Fleming (2012) found that maternal early life adversity was indirectly associated with maternal sensitivity via two pathways of HPA functioning, as well as HPA functioning and working memory combined. Thus, although the finding in the current study was significant for perceived parenting stress and not household chaos, it is consistent with recent work highlighting the influence of updating on other parenting constructs.

In this study, shifting functions did not show a significant effect for either conceptualization of parenting stress. It is possible that shifting is related to some but not all parenting outcomes, with relatively weaker relations to parenting stress as suggested by the 
current findings. For example, higher shifting scores have been shown to be positively associated with maternal sensitivity as well as emotional availability (in a substance-using sample) (Chico et al. 2014; Porreca et al., 2018). Also in a substance-using sample, Håkansson et al., 2018 found a relation between lower shifting performance and low parental reflective functioning, when controlling for IQ and mental health. However, Rutherford et al. (2018) found a significant relation between shifting and some but not all aspects of reflective functioning in a high-risk sample. Specifically, in this study, shifting was associated with greater interest and curiosity in child's thoughts and feelings, but not other aspects of reflective functioning. While these results suggest that shifting may be associated with some parenting outcomes, it may be less strongly related to parenting stress. It is also possible that the strength of the observed effect in our study was obscured due to limited variance in the shifting measure. Mean performance on the TrailMaking Task was average for participants in this study. More complex measures, such as the Wisconson Card Sorting Task may have yielded more variability. Further research examining different/multiple measures of shifting may help to further elucidate the role of shifting in parenting stress and potential moderators of this effect.

4.1.1 Specifying the Parenting Stress Construct. It is notable that the perceived parenting stress measure used in this study (PSI-4-SF) focused on maternal perceptions of their stressors within the parenting role using a P-C-R conceptualization of parenting stress. Mothers with reduced ability to inhibit their negative emotions, thoughts and behavioural responses to difficult child-care scenarios may be more likely to view the parenting role as stressful. They may experience stronger and more frequent negative reactions to their children's negative behaviours (e.g., crying, tantrums) or other difficult caregiving situations. In turn, these stronger responses (i.e., anger) may worsen already negative child-caregiver interactions, exacerbating 
maternal impressions of their difficulties and/or lack of efficacy as a parent. Numerous studies have identified a role for rumination and negative self-appraisals in maternal bonding and parenting behaviours (Dejong, Fox, \& Stein, 2016). These findings are in keeping with hypotheses that low capacity to inhibit rumination or negative self-appraisals in the parenting role likely contributes to negative parenting responses and by extension, perceived parenting stress.

In this study, the CHAOS measure was more focused on environmental and behavioural indicators of household chaos, including lack of routine and chaotic daily life (Matheny Jr. et al., 1995). It was hypothesized that maternal inhibition would be linked to household chaos as it was proposed that mothers would need to be able to inhibit their own negative emotional or behavioural responses in order to establish a calm predictable household. It was also suggested that mothers with stronger capacity to inhibit prepotent responses inconsistent with plans or routines, would be more effective in reducing household chaos. However, results of this study suggest that inhibition may not play a significant role with regards to DH indicators of stress. This finding, however, needs to be replicated with a larger sample to ensure results are not due to issues of statistical power.

With regard to maternal updating capacities, the current findings suggest that reduced updating performance may also exacerbate maternal perceptions of parenting being difficult and stressful. This may be because mothers who have relatively more challenge holding and manipulating information may also perceive difficulties in planning and implementing caregiving tasks. When updating performance is lower, mothers may show reduced capacity to recall their child's previous responses, and adapt appropriately and sensitively to their current needs. This view is consistent with findings that greater updating difficulties have significant 
associations with maternal sensitivity and reflective functioning (Håkansson et al., 2018, SturgeApple et al., 2016). Since lower maternal updating capacity increases the likelihood of negative interactions between child and parent, it may also intensify parenting stress for mothers with problematic substance use.

By contrast, updating performance was not associated with household chaos in the current study. This is surprising given that updating has been linked with laboratory-based planning tasks and is also believed to regulate the ability to integrate step-by-step planning into larger end goals (Baddley, 2007), skills that are likely required in reducing household chaos. At the same time, the establishment of routines and order within the household, while initially requiring updating/planning abilities might require less of this function overtime. Thus, mothers with relatively more challenges with updating may still be able to follow through on existing routines, making this function potentially less relevant to household chaos on an ongoing basis. Overall, additional study is needed to clarify the potential role of updating on DH conceptualizations of parenting stress, such as household chaos.

\subsubsection{Additional Variables Contributing to Parenting Stress.}

While executive functions were the primary focus of the study, the association of parenting stress with three additional variables (i.e., youngest child age, maternal depression, and SES) warrant discussion.

In our model of perceived parenting stress, age of youngest child was included as a covariate in the analysis, based on its correlation with the outcome variable, as well as findings in the literature supporting a negative association between child age and parenting stress (Neece et al., 2012; Williford et al., 2007). In my model, however, increases in child age were significantly related to increased parenting stress. This may suggest that child age may have 
differing effects depending on mothers' high-risk status, as the majority of studies to date including child age have focused on more typical maternal populations (Neece et al., 2012; Williford et al., 2007). It is possible that for high-risk mothers with problematic substance use, pressures associated with the need to access treatment and manage involvement with child welfare may increase parenting stress levels over time. This suggests that life stress may interact with child age to bring about heightened parenting stress. Further, it may be that as the motherinfant dyad experiences more relational challenges and child behavioral challenges become more apparent, parent stress increases (Harden, Denmark, Holmes, \& Duc, 2014). A recent metaanalysis ( $\mathrm{n}=133$ ) on the association between parenting stress and child symptomology recently tested child age as a moderator of parenting stress, and did not support an effect for child age (Barroso, Mendez, Graziano \& Bagner, 2018). The lack of effect identified in this review may reflect its focus on at-risk child clinical groups only (i.e., children with autism, ADHD, internalizing/externalizing symptoms or chronic illness), such that in these clinical cases the role of child dysfunction may outweigh any influence of child age. Both of these hypothesized models (i.e., life stess and increased child behavioral challenge) warrant further research attention.

A second variable that significantly contributed to the household chaos model of parenting stress was maternal depression. There is a vast literature associating maternal depression and parenting stress (Hur, Buettner, \& Jeon, 2015; Cicchetti et al., 1998; Crnic, Gaze, \& Hoffman, 2005; Shelleby et al., 2014). With regards to household chaos, it may be theorized that mothers who are depressed may contribute to higher levels of disorganization and chaos within the household that in turn impact maternal and child functioning (Hur, Buettner, \& Jeon, 2015). This relation was also identified in our study, with increased maternal depression being 
significantly linked to increases in household chaos. In turn, this pathway may lead to difficulties in child functioning. A recent longitudinal study of 731 mother-child dyads used structured equation modelling to identify a meditational pathway by which maternal income and depression in the preschool years, and household chaos during the kindergarten years predicted child conduct and emotional problems at ages 7 to 8 (Shelleby et al., 2014). Our study is in keeping with these findings and numerous additional works that have highlighted the important role of maternal depression in perpetuating family stress (Lovejoy et al., 2000). While no additional variance in household chaos was accounted for by executive functions above and beyond depression and SES, it is possible that the presence of depressive symptoms may have obscured any relation between executive functions and household chaos. Maternal depression has been associated with challenges in executive functions (Royall, Palmer, Chiodo \& Polk, 2012). Future research that addresses the interaction of these factors and their impact on household stress may be helpful in understanding the variance accounted for by each.

Finally, findings of the research reconfirm the significant positive relation between SES and parenting stress. This is consistent with previous research that has shown a significant relation between SES and household chaos, including multiple aspects of chaos (e.g., noise, crowding, unpredictability) (Evans, Eckenrode, \& Marcynyszyn, 2010). With regards to perceived parenting stress, mothers who experience lack of access to basic needs show greater chronic stress (Deater-Deckard, 2004). They are more likely to experience discrepancies between their actual and desired levels of resources for caregiving, and are less likely to engage in sensitive, supportive and stimulating caregiving (Deater-Deckard, 2004). Thus, SES may contribute to both increased levels of parenting distress, as well as greater impacts on parentchild dysfunction in particular (Reitman, Currier, \& Stickle, 2002). Low SES may also combine 
with other risk factors to increase parenting stress in an additive fashion. In their study, Steele et al. (2016) showed that low income was a significant predictor of perceived parenting stress, but that even greater impacts were shown when parents also reported significant exposure to averse childhood experiences. SES also has been shown to be significantly related to maternal EF (Hackman \& Farah, 2009). Findings of the current study suggest that executive functions contribute unique variance above and beyond SES and are therefore worthy of continued research, particularly regarding perceived parenting stress. In future studies, SES should also be explored in the context of additional risk factors to improve modelling of parenting stress outcomes. Importantly, SES has frequently been found to act as a moderator between executive functions and parenting outcomes, with lower SES status increasing the likelihood of executive function impacts. This is in keeping with findings of Deater-Deckard and colleagues (2012) who found that executive functions influenced household chaos only for low-SES samples. The results of this study are consistent with these results. Yet, as SES was a significant predictor for both models in this study (i.e., perceived parenting stress and household chaos), it can be understand as a potentially potent predictor of parenting stress in and of itself.

\subsection{Methodological Limitations and Future Directions}

While this study advances our understanding of the relation between executive functions and parenting stress and addresses some methodological limitations in the extant literature, there are important additional considerations that will need to be attended to in future research.

4.2.1 Directionality of Relations. While modeling in this study theorized executive functions (and additional maternal characteristics) as predictors of parenting stress, it is important to note that this study was ultimately cross-sectional, and as such no directionality or causality can be interpreted from these results. Specifically, any causality between the predictors 
and outcomes may be in either direction, or associated with a third, unidentified variable (Field, 2009).

There is certainly reason to consider a potential role for parenting stress in influencing executive functioning. Sources of chronic stress are associated with reduced cognitive control (Ohman, Nordin, Bergdahl, Birgander, \& Stigsdotter Neely, 2007). For example, early life stress has been associated with reduced development of executive functions, likely as a result of neurological sensitivity during brain maturation (Mueller et al., 2010; Pechtel \& Pizzagalli, 2011). Post-traumatic stress has also been associated with small impairments in inhibition and attention (Aupperle, Melrose, Stein, \& Paulus, 2012). Given high-levels of cumulative risk in this sample, maternal executive functioning may have been undermined by these stress-related processes. Notably, the impacts of early life stress or ongoing chronic stress would likely have contributed to of executive function established prior to women entering into the parenting role, and are thus not inconsistent with our hypotheses. However, future work might examine the degree to which stress increases related to the parenting role may undermine executive function performance. With regards to the role of PTSD, traumatic symptomology may occur before or after the onset motherhood, suggesting that future studies should endeavor to consider the potential influence of PTSD in further predicting parenting stress outcomes.

In addition, a robust literature points to the role of acute stress in reducing executive functions. Theoretically, the impact of acute stress may be due to a biasing of attention away from cognitive control processes and toward the stressor, or be the result of shifting from topdown (i.e., executive control) functions to increased bottom-up, or automatic processing (Gagnon \& Wagner, 2016; Mather \& Sutherland, 2011). Interestingly, the impact of acute stress on executive functions is likely differential. In their recent meta-analysis, Shields and colleagues 
(2016) reported that acute stress were linked with reductions in cognitive flexibility and working memory, but related to enhancements in inhibition. For our study, executive function testing did not include an acute stress paradigm and as such, the effects of acute stress are less relevant to our models. Yet, recent work has highlighted that executive function may be impacted differently across individuals, such that the capacity to maintain executive functions under stress may be particularly relevant to stress reactivity and coping, and that this effect may be mediated by the role of executive functions in generating perceptions of stressors as less severe (Shields, Moons, \& Slavich, 2017). This research suggests that future work might benefit from the measurement of executive functions under acute stress to determine if performance in these contexts better predict parenting stress outcomes. Ultimately, it may be that the relations between executive functioning and parenting stress are bidirectional with acute and chronic stressors related to the parenting role further undermining maternal executive functioning and contributing to reduced resilience to stress over time. The implementation of prospective longitudinal work or treatment-based studies to investigate changes to executive functions and parenting stress across time could be particularly useful in untangling these interactions.

4.2.2 Measurement of Executive Functions. This study suggests potential differential contributions of inhibition and updating to perceived parenting stress; however, these results should be interpreted with caution. 'Pure measures' of the three executive functions have yet to be identified. Rather, it is understood that existing tasks often measure multiple executive functions, as well as other related cognitive processes (McCabe, Roediger, McDaniel, Balota \& Hambrick, 2010; Friedman \& Miyake, 2017). Such is also the case for measures utilized in this study. While efforts were made to select tasks that were primary measures of each function, task impurity can be understood to have occurred. With regards to updating functions, although span 
tasks are frequently used as measures of working memory, there are indications that these tasks also measure attentional control capacities, and are predictive of other high level cognitive capacities such as processing speed (McCabe et al., 2011). Similarly, variants of the Stop Signal Task used to measure inhibition in this study have been found to be influenced by attentional factors, as well as motivational biases and strategic decision-making around the trade-off of speed vs. accuracy of responding (Marzke, Hughes, Badcock, Michie \& Heathcote, 2017; Leotti \& Wager, 2010). Finally, investigations of the construct validity of the Trail-Making Task are somewhat discrepant, with indications that this task measures updating, inhibition and/or shifting functions depending on the study (Kortte, Horner, \& Windham, 2002; Latzman \& Markon, 2010; Sanchez-Cubillo et al., 2009.) Indeed, when completing the Trail-Making Task, participants need to inhibit prepotent lists of the alphabet or numbers and hold and manipulate these lists in mind, while flexibly switching between lists. This challenge of construct validity is not limited to the Trail-Making Task but rather extends to the majority of executive function tasks. To address this limitation of current executive function tasks, it has been recommended that multiple measures of each executive function be used and examined in terms of their shared variability and impact on outcome measures (Miyake et al., 2000; Friedman \& Miyake, 2017). This was a limitation in the present research that should be addressed in future studies to further specify our understanding of the relation between specific executive functions and parenting stress outcomes.

4.2.3 Measurement of Executive Functions: The Role of Emotion. It has been argued that given the role of executive function in the regulation and coordination of cognitive processes, it is likely that emotion regulation (i.e. the capacity to change the duration or intensity of dominant emotional responses) influences executive function (Schmeichel \& Tang, 2015). 
With regards to parenting, Crandall and colleagues (2015) have noted that both maternal cognitive control (i.e., executive function) and maternal emotion control (i.e., emotional regulation) are both critical to sensitive and effective parenting behaviours. They argue further for a conceptual framework that includes both cognitive and emotional control in terms of the influence of parenting self-regulatory capacity on parenting behaviours. One approach to evaluating the interaction between emotion regulation and executive function involves the investigation of 'hot' executive functions that include integration of emotional stimuli into processing, or 'cold' executive functions that do not (Fonseca et al., 2012). For example, Monn and colleagues (2017) used a Stop Signal Task with an emotional induction component wherein participants received points for correct responses and lost points for errors to induce anxiety and frustration. Using this Task, the study identified a significant association between 'hot' inhibitory control (i.e., the capacity to inhibit responses despite feeling anxious and frustrated) and positive parenting practices for high-risk mothers at all levels of perceived life stress. The current study investigated 'cold' executive functions only; however, future research is needed to examine the role of emotion regulation and 'hot' executive function on parenting stress outcomes for mothers with problematic substance use. This work is particularly relevant in a sample of mothers with problematic substance use, as emotion regulation has been identified a significant challenge for many in this population, including as an early risk and maintenance factor for ongoing substance use (Kober \& Bolling, 2014).

One challenge that will need to be met in the field is the development of 'hot' executive function tasks that are emotionally salient for this population. In the developmental psychopathology literature, most 'hot' executive function tasks have relied on the use of emotional stimuli such as distressed child faces (e.g., Patterson et al., 2016). This is a challenge 
for women with problematic substance use, as research suggests that many of these mothers show reduced reactivity to infant emotional cues (faces and cries) compared to non-substance using mothers, making the creation of emotionally-salient trials for this population potentially more difficult (Landi et al., 2011). As such, advancing our understanding of the role of 'hot' executive functions on parenting stress and parenting behaviours more broadly will require careful development of measures with adequate physiological or neurological testing to ensure that they are sufficiently emotionally-arousing for mothers with problematic substance use.

4.2.4 Parenting Stress: A Complex Construct. In this research, a broad self-report measure of parenting stress (the PSI-SF-4, reflective of the P-C-R model) evaluated participants' perceptions of their parental distress, as well as other stressors related to the mother-child dyad. Yet, the use of a self-report measure of parenting perceptions alone may be considered insufficient to characterize the stress processes impacting parental functioning, particularly when mothers may have low insight (e.g., limited positive parenting knowledge or modelling), or tendencies to avoid emotionally stressful stimuli (e.g., emotionally avoidant language) - both factors which have already been identified in this population (Borelli et al., 2012; Velez et al., 2004). As such, household chaos was also included in this study to assess behavioural and environmental indicators of household stress. In this study, the correlation between parenting stress and household stress was moderate $(r=.551, \mathrm{p}<.001)$, which is consistent with previous reports identifying these outcomes as separate but related constructs (Dumas et al., 2005). Thus, not all mothers with high levels of perceived parenting stress, reported similarly high levels of household chaos, and poor maternal executive function was found to only exacerbate perceived parenting stress, indicating that executive functions may influence parenting stress outcomes differentially. 
By examining parenting stress and household stress using P-C-R and DH approaches, this study conceptualized stress in terms of a number of stress correlates, without direct measurement of the psychophysiological processes that are at the center of the biological stress response (Lazarus, 1999). Recent work investigating the role of maternal stress physiology (HPA and vagal functioning) points to links between self-reported stress and physiological stress indicators, and the value of biological indicators in the predication of many parenting and child outcomes (Padden, Concialdi-McGlynn, \& Lydon, 2018). As such, future work investigating the role of executive function in parenting stress could be furthered by integrating psychophysiological measures of stress, such as heart rate variability and skin conductance that may provide a more sensitive measure of 'in the moment' stress. Such measures could be employed particularly in the context of acute stressor paradigms, in which mothers and their children would be placed in controlled, and somewhat stressful scenarios (e.g., removal of a favored toy) to evaluate maternal reactivity and regulation in the context of parenting stress.

The discrepancy in findings between the correlation results that did not control for covariates and the regression analyses that did, highlight the importance of considering variance accounted by SES, age of child, and maternal depression when examining the relation between executive functions and parenting stress. There are other covariates, beyond those examined in the present study, that may also be worthy of exploration. For example, anxiety, PTSD, and experience of childhood trauma are common in mothers with problematic substance use (Zilberman et al., 2003; Trull et al., 2000; Hien et al., 2005) and may also be related to executive functions and parenting stress. Moreover, as child welfare involvement remains quite high for mothers with problematic substance use, security of child custody may also moderate outcomes. Likewise, factors such as family size, maternal IQ and maternal physical health may also interact 
with poor executive function to exacerbate parenting stress in both P-C-R and DH frameworks, and as such, require more research. Given these multiple risk factors, one approach to future research could be to employ a cumulative risk approach that identifies and sums known risks to determine the effect of the accumulation of a number of factors on parenting stress (Nair et al., 2003). Notably, a larger sample size than was used in this study would be required to adequately power such analyses.

\subsection{Implications for Clinical Practice}

While the role of executive functions in parenting stress outcomes requires further study, the findings of this research suggest a potential value in assessing and targeting maternal executive functions in treatment programs for mothers with problematic substance use. By identifying potential executive function challenges early in treatment, providers may be able to recognize mothers at higher risk for perceived parenting stress and other parenting difficulties. Identification processes are necessary, as increased difficulties with executive functions should not be assumed in this population. In the current study, for example, there was considerable variance in task performance across participants, with many mothers performing in the normal range for all three tasks. As such, it is important not to assume that all women share the same executive function challenges, but rather to screen/assess for executive functions in order to provide individualized accommodations that may support positive parenting behaviours and reduce parenting stress.

Existing treatment models may benefit from efforts to support mothers in improving and managing their executive function challenges, particularly inhibition and updating challenges, with the potential for improved parenting and child outcomes. Notably, many treatment sites may already be providing services that support and enhance executive functions. A recent study 
of focus groups of mothers in integrated addictions and parenting treatment revealed that therapeutic supports identified as helpful often contributed to support or enhancement of executive function capacities, with counselors providing a range of cuing, reminding, goalsetting, planning, and organizational skills (Milligan, Usher \& Urbanoski, 2017). It is important to note that these supports have been developed based on clinical practice insights in the absence of a theoretical and research-supported framework. As such, education of counselors, practical assessment tools, and a clear theoretical framework for treatment that guides intervention approaches to accommodate for and support the development of executive functions would require development in order to support this focus (Milligan et al., 2017).

Additionally, the findings of this study highlight the potential importance of addressing maternal depression and SES status within treatment contexts to reduce parenting stress. The value of addressing depression and SES difficulties in substance use treatment has been emphasized in a number of studies (e.g., Daughters et al., 2008; Hesse, 2009; Suchman \& Luthar, 2000), and our study supports this approach. A possible approach to strengthening treatment may be to implement existing evidence-based therapies with the potential to address depression, SES and executive functions concurrently. Problem-solving therapy and behavioural activation approaches for depression have the potential to target many of these factors; however, additional research is needed to establish their utility for maternal substance use populations and their impacts on executive function (Bell, \& D'Zurilla, 2009; Daughters et al., 2008;

MacPherson et al., 2010).

\subsection{Conclusion}

By investigating these relations using a sample of mothers with problematic substance use, the proposed study also represents an important research step toward improving knowledge 
of parenting in this specific population. This study found evidence for a relation between poor maternal executive functions and higher levels of parenting stress. Greater inhibition and updating challenges were linked to higher perceived parenting stress, with no identified effects on household chaos. The results of this study indicate that specificity of executive functions and parenting stress outcomes may be critical to furthering our understanding. It may be that maternal executive functions and parenting stress interact in a transactional, bidirectional relationship across time, with greater difficulties related to specific executive functions increasing the likelihood of parenting stress that in turn further undermine these functions. Studies that investigate changes in executive functions and parenting stress across time could be particularly useful in untangling such questions of directionality and how the relation between executive functions and parenting stress may change over time.

While it is too premature to suggest that executive function intervention may improve parenting stress, the current findings provide preliminary support that it may be an additional pathway of risk, in addition to already identified stressors (e.g., psychosocial stressors, emotion regulation challenges, reduced parenting knowledge and substance-related difficulties), that could be addressed in substance use treatment with women experiencing heightened parenting stress (Neger \& Prinz, 2015). Such work could also represent a promising step toward the improvement of parenting and child outcomes more generally given growing evidence of the role of intergenerational transmission of executive functions in predicting family trajectories, and for the role of parenting stress in exacerbating negative effects (Brieant et al., 2017; de Cock et al., 2017). 


\section{References}

Abidin, R. R. (1990). Parenting stress index-short form. Charlottesville, VA: Pediatric Psychology Press.

Abidin, R. R. (1992). The determinants of parenting behavior. Journal of clinical child psychology, 21(4), 407-412.

Ackerman, B. P., \& Brown, E. D. (2010). Physical and psychosocial turmoil in the home and cognitive development. In G. W. Evans \& T. D. Wachs (Eds.), Decade of behavior (science conference). Chaos and its influence on children's development: An ecological perspective (pp. 35-47). Washington, DC, US: American Psychological Association.

Ammerman, R. T., Shenk, C. E., Teeters, A. R., Noll, J. G., Putnam, F. W., \& van Ginkel, J. B. (2013). Multiple mediation of trauma and parenting stress in mothers in home visiting. Infant Mental Health Journal, 34, 234 -241.

Antony, M. M., Bieling, P. J., Cox, B. J., Enns, M. W., \& Swinson, R. P. (1998). Psychometric properties of the 42-item and 21-item versions of the Depression Anxiety Stress Scales in clinical groups and a community sample. Psychological assessment, 10(2), 176.

Antwi-Boasiako, K., King, B., Black, T., Fallon, B., Trocmé, N., \& Goodman, D. (2016). Ethno-racial Categories and Child Welfare Decisions: Exploring the Relationship with Poverty. CWRP Information Sheet \#178E. Toronto, ON: Canadian Child Welfare Research Portal.

Atkinson, L., Leung, E., Goldberg, S., Benoit, D., Poulton, L., \& Myhal, N. (2009). Attachment and selective attention: Disorganization and emotional Stroop reaction time. Developmental Psychopathology, 21, 99-126. 
Aupperle, R. L., Melrose, A. J., Stein, M. B., \& Paulus, M. P. (2012). Executive function and PTSD: disengaging from trauma. Neuropharmacology, 62(2), 686-694.

Aytaclar, S., Tarter, R. E., Kirisci, L., \& Lu, S. (1999). Association between hyperactivity and executive cognitive in childhood and substance use in early adolescence. Journal of the American Academy of Child \& Adolescent Psychiatry, 38(2), 172-178.

Azar, S. T., McGuier, D. J., Miller, E. A., Hernandez-Mekonnen, R., \& Johnson, D. R. (2017).

Child neglect and maternal cross-relational social cognitive and neurocognitive disturbances. Journal of Family Psychology, 31(1), 8.

Banich, M. T. (2009). Executive function: The search for an integrated account. Current directions in psychological science, 18(2), 89-94.

Barnet, B., Duggan, A. K., Wilson, M. D., \& Joffe, A. (1995). Association between postpartum substance use and depressive symptoms, stress, and social support in adolescent mothers. Pediatrics, 96(4), 659-666.

Barrett, J., \& Fleming, A. S. (2011). Annual research review: All mothers are not created equal: Neural and psychobiological perspectives on mothering and the importance of individual differences. Journal of Child Psychology and Psychiatry, 52(4), 368-397.

Barroso, N. E., Mendez, L., Graziano, P. A., \& Bagner, D. M. (2018). Parenting stress through the lens of different clinical groups: a systematic review \& meta-analysis. Journal of abnormal child psychology, 46(3), 449-461.

Beaufort, I. N., De Weert-Van Oene, G. H., Buwalda, V. A., de Leeuw, J. R. J., \& Goudriaan, A. E. (2017). The Depression, Anxiety and Stress Scale (DASS-21) as a Screener for Depression in Substance Use Disorder Inpatients: A Pilot Study. European addiction research, 23(5), 260-268. 
Behnke, M., Smith, V. C., \& Committee on Substance Abuse. (2013). Prenatal substance abuse: short-and long-term effects on the exposed fetus. Pediatrics, 131(3), e1009-e1024.

Bell, A. C., \& D'Zurilla, T. J. (2009). Problem-solving therapy for depression: a metaanalysis. Clinical psychology review, 29(4), 348-353.

Berger, L.M., Slack, K.S., Waldfogel, J., \& Bruch, S.K. (2010). Caseworker-perceived caregiver substance abuse and child protective services outcomes. Child Maltreatment, 15(3), 199210.

Blow, A. J., Gorman, L., Ganoczy, D., Kees, M., Kashy, D. A., Valenstein, M., ... \& Chermack, S. (2013). Hazardous drinking and family functioning in National Guard veterans and spouses postdeployment. Journal of Family Psychology, 27(2), 303.

Borelli, J. L., West, J. L., Decoste, C., \& Suchman, N. E. (2012). Emotionally avoidant language in the parenting interviews of substance-dependent mothers: Associations with reflective functioning, recent substance use, and parenting behavior. Infant Mental Health Journal, 33(5), 506-519.

Brieant, A., Holmes, C. J., Deater-Deckard, K., King-Casas, B., \& Kim-Spoon, J. (2017). Household chaos as a context for intergenerational transmission of executive functioning. Journal of adolescence, 58, 40-48.

Brown, S. A., \& Tapert, S. F. (2004). Adolescence and the trajectory of alcohol use: basic to clinical studies. Annals of the New York Academy of Sciences, 1021(1), 234-244.

Buckingham-Howes, S., Berger, S. S., Scaletti, L. A., \& Black, M. M. (2013). Systematic review of prenatal cocaine exposure and adolescent development. Pediatrics, 131(6), e1917e1936. 
Bugental, D. B., \& Johnston, C. (2000). Parental and child cognitions in the context of the family. Annual review of psychology, 51(1), 315-344.

Canadian Network of Substance Abuse and Allied Professionals. (2013). Essentials of Women and Problematic Substance Use. Retrieved from http://www.addictionresearchchair.ca/wp-content/uploads/2011/10/PT-Essentials-ofWomen-Problematic-Substance-Use-2013-en.pdf

Channon, S., \& Green, P. S. S. (1999). Executive function in depression: the role of performance strategies in aiding depressed and non-depressed participants. Journal of Neurology, Neurosurgery \& Psychiatry, 66(2), 162-171.

Chen, X., Tyler, K. A., Whitbeck, L. B., \& Hoyt, D. R. (2004). Early sexual abuse, street adversity, and drug use among female homeless and runaway adolescents in the Midwest. Journal of drug issues, 34(1), 1-21.

Chico, E., Gonzalez, A., Ali, N., Steiner, M., \& Fleming, A. S. (2014). Executive function and mothering: Challenges faced by teenage mothers. Developmental psychobiology, 56(5), 1027-1035.

Cicchetti, D., Rogosch, F. A., \& Toth, S. L. (1998). Maternal depressive disorder and contextual risk: Contributions to the development of attachment insecurity and behavior problems in toddlerhood. Developmentand Psychopathology, 10, 283-300.

Cohen, S., Glass, D.C., \& Singer, J.E. (1973). Apartment noise, auditory discrimination, and reading ability in children. Journal of Experimental Social Psychology, 9, 407-422.

Coldwell, J., Pike, A., \& Dunn, J. (2006). Household chaos-links with parenting and child behaviour. Journal of Child Psychology and Psychiatry, 47(11), 1116-1122. 
Corapci, F., \& Wachs, T.D. (2002). Does parental mood or efficacy mediate the influence of environmental chaos upon parenting behavior? Merrill Palmer Quarterly, 48, 182-201.

Costa, N. M., Weems, C. F., Pellerin, K., \& Dalton, R. (2006). Parenting stress and childhood psychopathology: An examination of specificity to internalizing and externalizing symptoms. Journal of Psychopathology and Behavioral Assessment, 28, 113-122.

Crandall, A., Deater-Deckard, K., \& Riley, A. W. (2015). Maternal emotion and cognitive control capacities and parenting: A conceptual framework. Developmental review, 36, $105-126$.

Crean, R. D., Crane, N. A., \& Mason, B. J. (2011). An evidence based review of acute and longterm effects of cannabis use on executive cognitive functions. Journal of addiction medicine, 5(1), 1 .

Crnic, K. A., Gaze, C., \& Hoffman, C. (2005). Cumulative parenting stress across the preschool period: Relations to maternal parenting and child behaviour at age 5. Infant and Child Development, 14(2), 117-132.

Crnic, K. A., \& Greenberg, M. T. (1990). Minor parenting stresses with young children. Child development, 61(5), 1628-1637.

Crnic, K. A., \& Low, C. (2002). Everyday stresses and parenting. Handbook of parenting Volume 5 Practical Issues in Parenting.

Cyr, C., Euser, E. M., Bakermans-Kranenburg, M. J., \& Van Ijzendoorn, M. H. (2010). Attachment security and disorganization in maltreating and high-risk families: A series of meta-analyses. Development and psychopathology, 22(1), 87-108. 
Dauber S, Neighbors C, Dasaro C, Riordan A, \& Morgenstern J. (2012). Impact of intensive case management on child welfare system involvement for substance-dependent parenting women on public assistance. Children and Youth Services Review, 34(7), 1359-1366.

Daughters, S. B., Braun, A. R., Sargeant, M. N., Reynolds, E. K., Hopko, D. R., Blanco, C., \& Lejuez, C. W. (2008). Effectiveness of a brief behavioral treatment for inner-city illicit drug users with elevated depressive symptoms: the life enhancement treatment for substance use (LETS Act!). Journal of Clinical Psychiatry, 69(1), 122.

Davis, R.N., \& Nolen-Hoeksema, S. (2000). Cognitive inflexibility among ruminators and non ruminators. Psychological Medicine, 24, 699-711.

Deater-Deckard, K. (2004). Parenting Stress. New Haven: Yale University Press.

Deater-Deckard, K., Chen, N., \& El Mallah, S. (2013). Parenting Stress. Oxford Bibliographies. Available at: http://www.oxfordbibliographies.com/view/document/obo9780199828340/obo-9780199828340-0142.xml

Deater-Deckard, K., Sewell, M. D., Petrill, S. A., \& Thompson, L. A. (2010). Maternal working memory and reactive negativity in parenting. Psychological science, 21(1), 75-79.

Deater-Deckard, K., Wang, Z., Chen, N., \& Bell, M. A. (2012). Maternal executive function, harsh parenting, and child conduct problems. Journal of Child Psychology and Psychiatry, 53, $1084-1091$.

DeJong, H., Fox, E., \& Stein, A. (2016). Rumination and postnatal depression: A systematic review and a cognitive model. Behaviour research and therapy, 82, 38-49.

Delis, D. C., Kaplan, E., \& Kramer, J. H. (2001). Delis-Kaplan Executive Function System ${ }^{(}(D-$ KEFS®): Examiner's Manual: Flexibility of Thinking, Concept Formation, Problem Solving, Planning, Creativity, Impulse Control, Inhibition. Pearson. 
Dennis, M. L., Titus, J. C., White, M. K., Unsicker, J. I., \& Hodgkins, D. (2003). Global appraisal of individual needs: Administration guide for the GAIN and related measures. Bloomington, IL: Chestnut Health Systems.

Dumas, J.E., Nissley, J., Nordstrom, A., Smith, E.P., Prinz, R.J., \& Levine, D.W. (2005). Home chaos: Sociodemographic, parenting, interactional, and child correlates. Journal of Clinical Child and Adolescent Psychology, 34, 93-104.

Dunn, M. G., Tarter, R. E., Mezzich, A. C., Vanyukov, M., Kirisci, L., \& Kirillova, G. (2002). Origins and consequences of child neglect in substance abuse families. Clinical Psychology Review, 22(7), 1063-1090.

Eisenberg, N., \& Spinrad, T. L. (2004). Emotion-related regulation: Sharpening the definition. Child development, 75(2), 334-339.

Evans, G. W., Eckenrode, J., \& Marcynyszyn, L. (2010). Poverty and chaos. Chaos and its Influence On Children's Development: An Ecological Perspective., 225-238.

Evans, G. W., \& Kim, P. (2007). Childhood poverty and health: cumulative risk exposure and stress dysregulation. Psychological Science, 18(11), 953-957.

Evans, G. W., \& Lepore, S. J. (2008). Psychosocial processes linking the environment and mental health. In H. Freeman \& S. Stansfeld (Eds.), The impact of the environment on psychiatric disorder (pp. 127-157). New York, NY, US: Routledge/Taylor \& Francis Group.

Field, A. (2009). Discovering statistics using SPSS. Sage publications.

Finkelstein, N. (1994). Treatment issues for alcohol-and drug-dependent pregnant and parenting women. Health \& Social Work, 19(1), 7-15. 
Flaks, M. K., Malta, S. M., Almeida, P. P., Bueno, O. F. A., Pupo, M. C., Andreoli, S., .. . Bressan, R. A. (2014). Attentional and executive functions are differentially affected by post-traumatic stress disorder and trauma. Journal of Psychiatric Research, 48(1), 32-39.

Friedman, N. P., \& Miyake, A. (2017). Unity and diversity of executive functions: Individual differences as a window on cognitive structure. Cortex, 86, 186-204.

Friedman, N. P., Miyake, A., Young, S. E., DeFries, J. C., Corley, R. P., \& Hewitt, J. K. (2008). Individual differences in executive functions are almost entirely genetic in origin. Journal of Experimental Psychology: General, 137(2), 201.

Gagnon, S. A., \& Wagner, A. D. (2016). Acute stress and episodic memory retrieval: neurobiological mechanisms and behavioral consequences. Annals of the New York Academy of Sciences, 1369(1), 55-75.

Goldstein, D. S. (1995). Stress as a scientific idea: A homeostatic theory of stress and distress. Homeostasis in Health and Disease, 36, 177-215.

Gonzalez, A., Jenkins, J. M., Steiner, M., \& Fleming, A. S. (2012). Maternal early life experiences and parenting: the mediating role of cortisol and executive function. Journal of the American Academy of Child \& Adolescent Psychiatry, 51(7), 673-682.

Government of Canada (2015). Canadian Tobacco, Alcohol and Drugs Survey, FebruaryDecember 2015. Retrieved from https://www.canada.ca/en/healthcanada/services/canadian-tobacco-alcohol-drugs-survey/2015-supplementary-tables.html

Grella, C. E., Hser, Y. I., \& Huang, Y. C. (2006). Mothers in substance abuse treatment: Differences in characteristics based on involvement with child welfare services. Child Abuse \& Neglect, 30(1), 55-73. 
Grenard, J. L., Ames, S. L., Wiers, R. W., Thush, C., Sussman, S., \& Stacy, A. W. (2008). Working memory capacity moderates the predictive effects of drug-related associations on substance use. Psychology of Addictive Behaviors, 22(3), 426.

Gustafsson, P. E., Anckarsäter, H., Lichtenstein, P., Nelson, N., \& Gustafsson, P. A. (2010). Does quantity have a quality all its own? Cumulative adversity and up-and downregulation of circadian salivary cortisol levels in healthy children. Psychoneuroendocrinology, 35(9), 1410-1415.

Hackman, D. A., \& Farah, M. J. (2009). Socioeconomic status and the developing brain. Trends in cognitive sciences, 13(2), 65-73.

Håkansson, U., Söderström, K., Watten, R., Skårderud, F., \& Øie, M. G. (2018). Parental reflective functioning and executive functioning in mothers with substance use disorder. Attachment \& human development, 20(2), 181-207.

Hansen, A.L., Johnsen, B.H., \& Thayer ,J.F. (2003). Vagal influence on working memory and attention. International Journal of Psychophysiology, 48, 263-274.

Harden, B., Denmark, N., Holmes, A., \& Duchene, M. (2014). Detached parenting and toddler problem behavior in early head start families. Infant Mental Health Journal, 35,(6).

Haskett, M.E., Ahern, L.S., Ward, C.S., \& Allaire, J.C. (2006). Factor structure and validity of the parenting stress index-short form. Journal of Clinical Child and Adolescent Psychology, 35, 302-12.

Hesse, M. (2009). Integrated psychological treatment for substance use and co-morbid anxiety or depression vs. treatment for substance use alone. A systematic review of the published literature. $B M C$ psychiatry, $9(1), 6$. 
Hayes, S. A., \& Watson, S. L. (2013). The impact of parenting stress: A meta-analysis of studies comparing the experience of parenting stress in parents of children with and without autism spectrum disorder. Journal of autism and developmental disorders, 43(3), 629642.

Hien, D., Cohen, L., \& Campbell, A. (2005). Is traumatic stress a vulnerability factor for women with substance use disorders? Clinical Psychology Review, 25(6), 813-823.

Holdnack, J. A., Zhou, X., Larrabee, G. J., Millis, S. R., \& Salthouse, T. A. (2011). Confirmatory factor analysis of the WAIS-IV/WMS-IV. Assessment, 18(2), 178-191.

Homack, S., Lee, D., \& Riccio, C. A. (2005). Test review: Delis-Kaplan executive function system. Journal of clinical and experimental neuropsychology, 27(5), 599-609.

Horrigan, T. J., Schroeder, A. V., \& Schaffer, R. M. (2000). The triad of substance abuse, violence, and depression are interrelated in pregnancy. Journal of substance abuse treatment, $18(1), 55-58$.

Hutchison, L., Feder, M., Abar, B., \& Winsler, A. (2016). Relations between parenting stress, parenting style, and child executive functioning for children with ADHD or autism. Journal of Child and Family Studies, 25(12), 3644-3656.

Hur, E., Buettner, C. K., \& Jeon, L. (2015). Parental depressive symptoms and children's schoolreadiness: the indirect effect of household Chaos. Journal of Child and Family Studies, 24(11), 3462-3473.

Johnson, A. D., Martin, A., Brooks-Gunn, J., \& Petrill, S. A. (2008). Order in the house! Associations among household chaos, the home literacy environment, maternal reading ability, and children's early reading. Merrill-Palmer quarterly, 54(4), 445. 
Johnsen, B.H., Hansen, A.L., Murison, R., \& Thayer, J.F. (2002). Heart rate variability is inversely related to cortisol reactivity during cognitive stress. Psychosomatic Medicine, $84,148$.

Joyner, K. B., Silver, C. H., \& Stavinoha, P. L. (2009). Relationship between parenting stress and ratings of executive functioning in children with ADHD. Journal of Psychoeducational Assessment, 27(6), 452-464.

Kelley, S. J. (1992). Parenting stress and child maltreatment in drug-exposed children. Child abuse \& neglect, 16(3), 317-328.

Kelley, S. J. (1998). Stress and coping behaviors of substance-abusing mothers. Journal for Specialists in Pediatric Nursing, 3(3), 103-110.

Killeen, T., \& Brady, K. T. (2000). Parental stress and child behavioral outcomes following substance abuse residential treatment: Follow-up at 6 and 12 months. Journal of substance abuse treatment, 19(1), 23-29.

Landi, N., Montoya, J., Kober, H., Rutherford, H., Mencl, E., Worhunsky, P., ... \& Mayes, L. (2011). Maternal neural responses to infant cries and faces: relationships with substance use. Frontiers in psychiatry, 2, 32.

Latzman, R. D., \& Markon, K. E. (2010). The factor structure and age-related factorial invariance of the Delis-Kaplan Executive Function System (D-KEFS). Assessment, 17(2), 172-184.

Lazarus, R. S. (1999). Stress and Emotion: A New Synthesis. New York: Springer.

Lazarus, R.S., \& Folkman, S. (1984). Stress, Appraisal, and Coping. New York, NY: Springer.

Leigh, B., \& Milgrom, J. (2008). Risk factors for antenatal depression, postnatal depression and parenting stress. BMC psychiatry, 8(1), 24. 
Liles, B. D., Newman, E., LaGasse, L. L., Derauf, C., Shah, R., Smith, L. M., ... \& DellaGrotta, S. (2012). Perceived child behavior problems, parenting stress, and maternal depressive symptoms among prenatal methamphetamine users. Child Psychiatry \& Human Development, 43(6), 943-957.

Lovallo, W. R. (2006). Cortisol secretion patterns in addiction and addiction risk. International Journal of Psychophysiology, 59(3), 195-202.

Lovejoy, M. C., Graczyk, P. A., O'Hare, E., \& Neuman, G. (2000). Maternal depression and parenting behavior: A meta-analytic review. Clinical psychology review, 20(5), 561-592.

Lovibond, P. F., \& Lovibond, S. H. (1995). The structure of negative emotional states: Comparison of the Depression Anxiety Stress Scales (DASS) with the Beck Depression and Anxiety Inventories. Behaviour research and therapy, 33(3), 335-343.

Loyd, B. H., \& Abidin, R. R. (1985). Revision of the parenting stress index. Journal of Pediatric Psychology, 10(2), 169-177.

MacPherson, L., Tull, M. T., Matusiewicz, A. K., Rodman, S., Strong, D. R., Kahler, C. W., ... \& Lejuez, C. W. (2010). Randomized controlled trial of behavioral activation smoking cessation treatment for smokers with elevated depressive symptoms. Journal of consulting and clinical psychology, 78(1), 55.

Madoz-Gúrpide, A., Blasco-Fontecilla, H., Baca-García, E., \& Ochoa-Mangado, E. (2011). Executive dysfunction in chronic cocaine users: An exploratory study. Drug and Alcohol Dependence, 117(1), 55-58.

Margalit, M., \& Kleitman, T. (2006). Mothers’ stress, resilience and early intervention. European Journal of Special Needs Education, 21(3), 269-283. 
Matheny, A. P., Jr., Wachs, T. D., Ludwig, J. L., \& Phillips, K. (1995). Bringing order out of chaos: Psychometric characteristics of the confusion, hubbub, and order scale. Journal of Applied Developmental Psychology, 16, $429-444$.

Mather, M., \& Sutherland, M. R. (2011). Arousal-biased competition in perception and memory. Perspectives on psychological science, 6(2), 114-133.

Matusiewicz, A. K., Macatee, R. J., Guller, L., \& Lejuez, C. W. (2013). Impulsivity and Addiction in Parents. In Nancy E. Suchman, Marjukka Pajulo \& Linda Mayes (Eds.) Parenting and Substance Abuse: Developmental Approaches to Intervention (pp. 44-62). Oxford University Press.

Mayer, M., Lavergne, C., \& Baraldi, R. (2004). Substance abuse and child neglect: Intruders in the family. CECW Information Sheet \#14E. Montreal, QC, Canada: Université de Montréal and Institut pour le développement social des jeunes.

Mayes, L. C., \& Fahy, T. (2001). Prenatal drug exposure and cognitive development. In R. J. Sternberg, \& E. L. Grigorenko (Eds.), Environmental effects on cognitive abilities; environmental effects on cognitive abilities (pp. 189-219). Lawrence Erlbaum Associates Publishers, Mahwah, NJ.

Mello, N. K. (2010). Hormones, nicotine, and cocaine: clinical studies. Hormones and behavior, 58(1), 57-71.

Milgrom, J., \& McCloud, P. (1996). Parenting stress and postnatal depression. Stress Medicine, $12(3), 177-186$.

Milligan K, Niccols A, Sword W, Thabane L, Henderson J, Smith A, Liu J. (2010). Maternal substance use and integrated treatment programs for women with substance abuse issues 
and their children: A meta-analysis. Substance Abuse Treatment, Prevention, and Policy, 5.

Milligan, K., Usher, A. M., \& Urbanoski, K. A. (2017). Supporting pregnant and parenting women with substance-related problems by addressing emotion regulation and executive function needs. Addiction Research \& Theory, 25(3), 251-261.

Misri, S., Reebye, P., Milis, L., \& Shah, S. (2006). The impact of treatment intervention on parenting stress in postpartum depressed mothers: a prospective study. American journal of orthopsychiatry, 76(1), 115-119.

Mittal, C., Griskevicius, V., Simpson, J. A., Sung, S., \& Young, E. S. (2015). Cognitive adaptations to stressful environments: When childhood adversity enhances adult executive function. Journal of Personality and Social Psychology, 109(4), 604.

Miyake, A., Friedman, N. P., Emerson, M. J., Witzki, A. H., Howerter, A., \& Wager, T. D. (2000). The unity and diversity of executive functions and their contributions to complex "frontal lobe" tasks: A latent variable analysis. Cognitive psychology, 4l(1), 49-100.

Miyake, A., Friedman, N. P., Rettinger, D. A., Shah, P., \& Hegarty, M. (2001). How are visuospatial working memory, executive functioning, and spatial abilities related? A latent-variable analysis. Journal of experimental psychology: General, 130(4), 621.

Molitor, A., Mayes, L. C., \& Ward, A. (2003). Emotion regulation behavior during a separation procedure in 18-month-old children of mothers using cocaine and other drugs. Development and Psychopathology, 15(1), 39-54.

Monn, A. R., Narayan, A. J., Kalstabakken, A. W., Schubert, E. C., \& Masten, A. S. (2017). Executive function and parenting in the context of homelessness. Journal of Family Psychology, 31(1), 61-70. 
Motz, M., Leslie, M., Pepler, D. J., Moore, T. E., \& Freeman, P. A. (2006). Breaking the Cycle: measures of progress 1995-2005. J FAS Int, 4(Suppl), e22.

Mozzambani, A. C. F., Fuso, S. F., Malta, S. M., Ribeiro, R. L., Pupo, M. C., Flaks, M. K., \& Mello, M. F. (2017). Long-term follow-up of attentional and executive functions of PTSD patients. Psychology \& Neuroscience, 10(2), 215-224.

Mueller, S. C., Maheu, F. S., Dozier, M., Peloso, E., Mandell, D., Leibenluft, E., ... \& Ernst, M. (2010). Early-life stress is associated with impairment in cognitive control in adolescence: an fMRI study. Neuropsychologia, 48(10), 3037-3044.

Nair, P., Schuler, M. E., Black, M. M., Kettinger, L., \& Harrington, D. (2003). Cumulative environmental risk in substance abusing women: early intervention, parenting stress, child abuse potential and child development. Child Abuse \& Neglect, 27(9), 993-995.

National Centre on Addiction and Substance Abuse. (2003). The Formative Years: pathways to Substance Abuse among Girls and Young Women Ages 8-22. New York: CASA.

Neece, C. L., Green, S. A., \& Baker, B. L. (2012). Parenting stress and child behavior problems: A transactional relationship across time. American Journal on Intellectual and Developmental Disabilities, 117(1), 48-66.

Neger, E. N., \& Prinz, R. J. (2015). Interventions to address parenting and parental substance abuse: Conceptual and methodological considerations. Clinical psychology review, 39, 71-82.

Niccols, A., Milligan, K., Sword, W., Thabane, L., Henderson, J., \& Smith, A. (2012). Integrated programs for mothers with substance abuse issues: A systematic review of studies reporting on parenting outcomes. Harm reduction journal, 9(1), 14. 
Niccols A, Sword W. (2005). "New Choices" for substance-using mothers and their children: preliminary evaluation. Journal of Substance Use, 10(4), 239-251.

Obradović, J., Portilla, X. A., Tirado-Strayer, N., Siyal, S., Rasheed, M. A., \& Yousafzai, A. K. (2017). Maternal scaffolding in a disadvantaged global context: The influence of working memory and cognitive capacities. Journal of Family Psychology, 31(2), 139.

O'Connor, M. J., Kogan, N., \& Findlay, R. (2002). Prenatal alcohol exposure and attachment behavior in children. Alcoholism: Clinical and Experimental Research, 26(10), 15921602.

Öhman, L., Nordin, S., Bergdahl, J., Birgander, L. S., \& Neely, A. S. (2007). Cognitive function in outpatients with perceived chronic stress. Scandinavian journal of work, environment \& health, 223-232.

Padden, C., Concialdi-McGlynn, C., \& Lydon, S. (2018). Psychophysiological measures of stress in caregivers of individuals with autism spectrum disorder: a systematic review. Developmental neurorehabilitation, 1-15

Patterson, T. K., Lenartowicz, A., Berkman, E. T., Ji, D., Poldrack, R. A., \& Knowlton, B. J. (2016). Putting the brakes on the brakes: negative emotion disrupts cognitive control network functioning and alters subsequent stopping ability. Experimental brain research, 234(11), 3107-3118.

Peeters, M., Janssen, T., Monshouwer, K., Boendermaker, W., Pronk, T., Wiers, R., \& Vollebergh, W. (2015). Weaknesses in executive functioning predict the initiating of adolescents' alcohol use. Developmental cognitive neuroscience, 16, 139-146.

Pechtel, P., \& Pizzagalli, D. A. (2011). Effects of early life stress on cognitive and affective function: an integrated review of human literature. Psychopharmacology, 214(1), 55-70. 
Pentz, M. A., Shin, H., Riggs, N., Unger, J. B., Collison, K. L., \& Chou, C. P. (2015). Parent, peer, and executive function relationships to early adolescent e-cigarette use: a substance use pathway? Addictive behaviors, 42, 73-78.

Pinderhughes, E. E., Dodge, K. A., Bates, J. E., Pettit, G. S., \& Zelli, A. (2000). Discipline responses: Influences of parents' socioeconomic status, ethnicity, beliefs about parenting, stress, and cognitive-emotional processes. Journal of family psychology, 14(3), 380.

Ponnet, K., Wouters, E., Mortelmans, D., Pasteels, I., De Backer, C., Van Leeuwen, K., \& Van Hiel, A. (2013). The influence of mothers' and fathers' parenting stress and depressive symptoms on own and partner's parent-child communication. Family Process, 52, 312324.

Poole, N., \& Urquhart, C. (2010). Mothering and substance use: Approaches to prevention, harm reduction and treatment. Gendering the National Framework Series, 3.

Porreca, A., Biringen, Z., Parolin, M., Saunders, H., Ballarotto, G., \& Simonelli, A. (2018). Emotional Availability, Neuropsychological Functioning, and Psychopathology: The Context of Parental Substance Use Disorder. BioMed research international 2018.

Reitman, D., Currier, R. O., \& Stickle, T. R. (2002). A critical evaluation of the Parenting Stress Index-Short Form (PSI-SF) in a head start population. Journal of Clinical Child and Adolescent Psychology, 31(3), 384-392.

Rodning, C., Beckwith, L., \& Howard, J. (1991). Quality of attachment and home environments in children prenatally exposed to PCP and cocaine. Development and psychopathology, $3(4), 351-366$. 
Rodriguez, C.M. (2010). Personal contextual characteristics and cognitions: Predicting child abuse potential and disciplinary style. Journal of Interpersonal Violence, 25(2), 315335.

Royall, D. R., Palmer, R., Chiodo, L. K., \& Polk, M. J. (2012). Depressive symptoms predict longitudinal change in executive control but not memory. International journal of geriatric psychiatry, 27(1), 89-96.

Rutherford, H. J., Byrne, S. P., Crowley, M. J., Bornstein, J., Bridgett, D. J., \& Mayes, L. C. (2018). Executive functioning predicts reflective functioning in mothers. Journal of Child and Family Studies, 27(3), 944-952.

Rutherford, H., Potenza, M. N., \& Mayes, L.C. (2013). The neurobiology of addiction and attachment. In Nancy E. Suchman, Marjukka Pajulo \& Linda Mayes (Eds). Parenting and Substance Abuse: Developmental Approaches to Intervention (pp. 3-23). Oxford University Press.

Rutherford, H., Williams, S., Moy, S., Mayes, L., \& Johns, J. (2011). Disruption of maternal parenting circuitry by addictive process: rewiring of reward and stress systems. Frontiers in psychiatry, 2, 37.

Salo, S., Politi, J., Tupola, S., Biringen, Z., Kalland, M., Halmesmäki, E., . . Kivitie-Kallio, S. (2010). Early development of opioid-exposed infants born to mothers in buprenorphinereplacement therapy. Journal of Reproductive and Infant Psychology, 28(2), 161-179.

Schempf, A. H. (2007). Illicit drug use and neonatal outcomes: a critical review. Obstetrical \& Gynecological Survey, 62, 749-757. 
Shaffer, A., \& Obradović, J. (2017). Unique contributions of emotion regulation and executive functions in predicting the quality of parent-child interaction behaviors. Journal of Family Psychology, 31(2), 150.

Shapero, B. G., \& Steinberg, L. (2013). Emotional reactivity and exposure to household stress in childhood predict psychological problems in adolescence. Journal of Youth and Adolescence, 42(10), 1573-82.

Shields, G. S., Sazma, M. A., \& Yonelinas, A. P. (2016). The effects of acute stress on core executive functions: a meta-analysis and comparison with cortisol. Neuroscience \& Biobehavioral Reviews, 68, 651-668.

Sheinkopf, S. J., Lester, B. M., LaGasse, L. L., Seifer, R., Bauer, C. R., Shankaran, S., ... \& Wright, L. L. (2005). Interactions between maternal characteristics and neonatal behavior in the prediction of parenting stress and perception of infant temperament. Journal of Pediatric Psychology, 31(1), 27-40.

Shelleby, E. C., Votruba-Drzal, E., Shaw, D. S., Dishion, T. J., Wilson, M. N., \& Gardner, F. (2014). Income and children's behavioral functioning: A sequential mediation analysis. Journal of Family Psychology, 28(6), 936.

Shields, G. S., Moons, W. G., \& Slavich, G. M. (2017). Better executive function under stress mitigates the effects of recent life stress exposure on health in young adults. Stress, 20(1), 92-102.

Sinclair, S. J., Siefert, C. J., Slavin-Mulford, J. M., Stein, M. B., Renna, M., \& Blais, M. A. (2012). Psychometric evaluation and normative data for the depression, anxiety, and stress scales-21 (DASS-21) in a nonclinical sample of US adults. Evaluation \& the Health Professions, 35(3), 259-279. 
Sinha, R. (2008). Chronic stress, drug use, and vulnerability to addiction. Annals of the New York Academy of Sciences, 1141(1), 105-130.

Snyder, H. R. (2013). Major depressive disorder is associated with broad impairments on neuropsychological measures of executive function: a meta-analysis and review. Psychological bulletin, 139(1), 81.

Söderström, K., \& Skårderud, F. (2009). Minding the baby. mentalization-based treatment in families with parental substance use disorder: Theoretical framework. Nordic Psychology, 61(3), 47-65.

Steele, H., Bate, J., Steele, M., Dube, S. R., Danskin, K., Knafo, H., ... \& Murphy, A. (2016). Adverse childhood experiences, poverty, and parenting stress. Canadian Journal of Behavioural Science/Revue canadienne des sciences du comportement, 48(1), 32.

Stucky, B. D., Edelen, M. O., \& Ramchand, R. (2014). A psychometric assessment of the GAIN Individual Severity Scale (GAIN-GISS) and Short Screeners (GAIN-SS) among adolescents in outpatient treatment programs. Journal of substance abuse treatment, 46(2), 165-173.

Sturge-Apple, M. L., Jones, H. R., \& Suor, J. H. (2017). When stress gets into your head: Socioeconomic risk, executive functions, and maternal sensitivity across childrearing contexts. Journal of Family Psychology, 31(2), 160.

Stuss, D. T., \& Alexander, M. P. (2000). Executive functions and the frontal lobes: a conceptual view. Psychological research, 63(3-4), 289-298.

Stuss, D. T. (2011). Functions of the frontal lobes: relation to executive functions. Journal of the international neuropsychological Society, 17(5), 759-765. 
Suchman, N. E., DeCoste, C., Leigh, D., \& Borelli, J. (2010). Reflective functioning in mothers with drug use disorders: Implications for dyadic interactions with infants and toddlers. Attachment \& human development, 12(6), 567-585.

Suchman, N. E., \& Luthar, S. S. (2000). Maternal addiction, child maladjustment and sociodemographic risks: implications for parenting behaviors. Addiction, 95(9), 1417-1428.

Tarter, R. E., Kirisci, L., Mezzich, A., Cornelius, J. R., Pajer, K., Vanyukov, M., ... \& Clark, D. (2003). Neurobehavioral disinhibition in childhood predicts early age at onset of substance use disorder. American Journal of Psychiatry, 160(6), 1078-1085.

Trull, T. J., Sher, K. J., Minks-Brown, C., Durbin, J., \& Burr, R. (2000). Borderline personality disorder and substance use disorders: A review and integration. Clinical psychology review, 20(2), 235-253.

Tufts, J. H. (1907). On the psychology of the family. Psychological Bulletin, 4(12), 371-374.

Valiente, C., Lemery-Chalfant, K., \& Reiser, M. (2007). Pathways to problem behaviors: Chaotic homes, parent and child effortful control, and parenting. Social Development, 16(2), 249-267.

Velez, M. L., Jansson, L. M., Montoya, I. D., Schweitzer, W., Golden, A., \& Svikis, D. (2004). Parenting knowledge among substance abusing women in treatment. Journal of substance abuse treatment, 27(3), 215-222.

Walsh, C., MacMillan, H. L., \& Jamieson, E. (2003). The relationship between parental substance abuse and child maltreatment: findings from the Ontario Health Supplement. Child abuse \& neglect, 27(12), 1409-1425. 
Wechsler, D., Coalson, D. L., \& Raiford, S. E. (2008). WAIS-IV. Wechsler Adult Intelligence Scale: Fourth Edition. Technical and interpretative manual. San Antonio, TX: NCS Pearson.

Whitesell, C. J., Teti, D. M., Crosby, B., \& Kim, B. (2015). Household chaos, sociodemographic risk, coparenting, and parent-infant relations during infants' first year. Journal of Family Psychology, 29(2), 211-220.

Whitmer, A. J., \& Banich, M. T. (2007). Inhibition versus switching deficits in different forms of rumination. Psychological science, 18(6), 546-553.

Williams, I. (1968). Some psychological stresses on women. Medical Journal of Australia, 2(3), 97-100.

Williams, P. G., Suchy, Y., \& Rau, H. K. (2009). Individual differences in executive functioning: implications for stress regulation. Annals of Behavioral Medicine, 37(2), 126-140.

Williford, A. P., Calkins, S. D., \& Keane, S. P. (2007). Predicting change in parenting stress across early childhood: Child and maternal factors. Journal of abnormal child psychology, 35(2), 251-263.

Zilberman, M. L., Tavares, H., Blume, S. B., \& El-Guebaly, N. (2003). Substance use disorders: sex differences and psychiatric comorbidities. The Canadian Journal of Psychiatry, 48(1), 5-13. 